Raúl Rodríguez García

\title{
La aportación regionalista en EE. UU. Génesis bibliográfica de una "nueva filosofía" arquitectónica
}

Palabras clave: EEUU, arquitectura moderna, regionalismo, tradición, escuela bahía de San Francisco.

Tras la Segunda Guerra Mundial, la arquitectura moderna se enfrentaba a una "encrucijada": los arquitectos tuvieron que elegir en general entre mantener su obediencia rígida a la arquitectura "funcionalista" o buscar nuevos medios de expresión. Si bien el Movimiento Moderno no había fracasado como tal, parecía evidente que si necesitaba algunas revisiones. Además, durante estos años en los EE. UU. se dio una gran multitud de interpretaciones regionales -o "regionalistas"- del Movimiento Moderno, siendo algunas de ellas grandes aportaciones genuinamente americanas a la modernidad. Este regionalismo cuestionaba la misma importancia del Estilo Internacional. Asi, muchos arquitectos europeos se vieron obligados a reevaluar sus carreras y sus principios, generando una "nueva filosofia" arquitectónica. Una década más tarde, aquellas reflexiones serian claves para un autor como Robert Venturi.

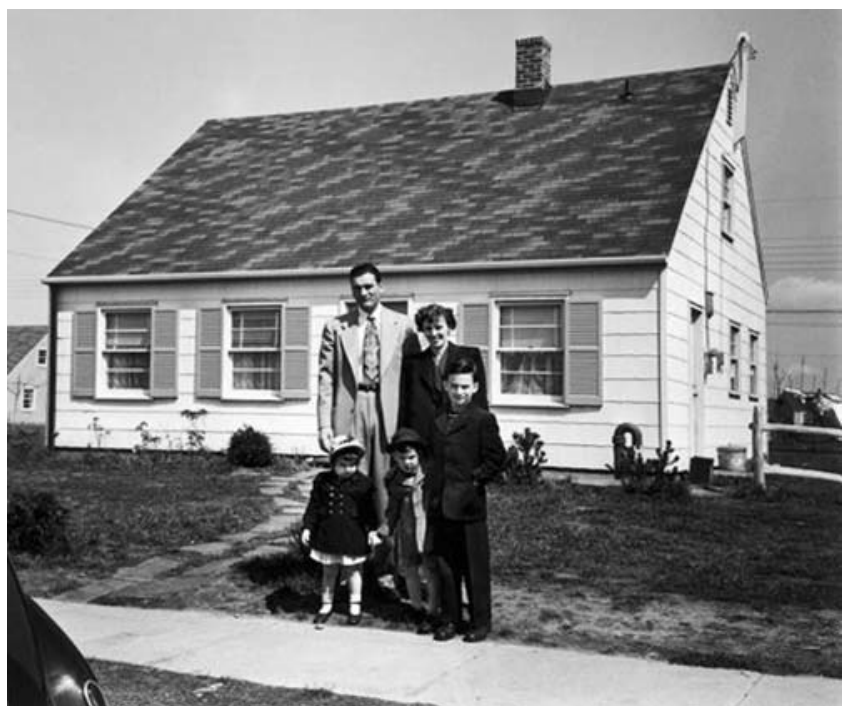

Figura 1.Familia Bernard Levey delante de su nuevo hogar en Levittown, Long Island (Nueva York). 1948. Fotógrafo: Bernard Hoffmann. Life Magazine.

Raúl Rodríguez García (UPM, 2007). Preparando Tesis Doctoral en ETSAM. Ha impartido clases de Expresión gráfica e Historia del arte $y$ de la arquitectura en la Universidad Nebrija de Madrid. Actualmente reside $y$ trabaja en Nueva York
Tras el final del período bélico de 1945, los años cincuenta se estrenaban en los Estados Unidos de América como una década de un cierto optimismo social y de crecimiento económico: fue la era de las grandes autopistas interestatales, del primer restaurante de comida rápida de los hermanos McDonald (1948), de Marilyn Monroe, de Elvis Presley, de los coches con grandes aletas... así como de fenómenos arquitectónicos de gran aceptación popular, como por ejemplo la creación de las Levittown ${ }^{1}$ (una iniciativa de William Levitt de 1946 quien, siguiendo las ideas de Frederick Taylor y Henry Ford, se propuso fabricar viviendas unifamiliares asequibles y eficientes para la familia media estadounidense, especialmente para los veteranos de la guerra, ya de regreso en el país). (figura 1).

Sin embargo en estos años inmediatamente posteriores a la Segunda Guerra Mundial, la arquitectura moderna se enfrentaba a una "encrucijada"
(Goldhagen y Legault. 2000). Muchos arquitectos empezaron a sentirse escépticos ante la capacidad del Estilo Internacional -dominante- para responder a las demandas sociales o humanísticas (un sentimiento magnificado por la pérdida de tantas vidas durante las grandes guerras), y abordaron la búsqueda de nuevas aproximaciones. La arquitectura racional auto-justificada no reflejaba la riqueza de la experiencia humana, irracional en muchas ocasiones. Y las múltiples llamadas a la "expresión" y la "monumentalidad" arquitectónicas revelaban la necesidad de un compromiso más humano que el que se entendía que ofrecía el Estilo Internacional (Barr et al. 1948).

De este modo, los arquitectos modernos de postguerra tuvieron que elegir en general entre mantener su obediencia rígida a la arquitectura "funcionalista", o buscar nuevos medios de expresión. En cierto sentido, estaban conscientemente comprometidos con el hecho de repensar lo que la arquitectura debía ser o hacer, e igualmente interesados en remodelar lo moderno para que se adaptase a un paisaje social modificado; aspiraban quizás a una arquitectura más "humana", sin abandonar la eficiencia tecnológica. Al tratar de sustituir la idea que los ciudadanos tenían pergeñada de la arquitectura, tomaron conciencia de la "inmadurez de la arquitectura moderna" y de la necesidad de "madurarla" (Barr et al. 1948). ${ }^{2}$ No obstante, si bien el Movimiento Moderno no había fracasado como tal, parecía evidente que sí necesitaba algunas revisiones. Parte de ellas serán esbozadas aquí. No obstante, a pesar del interés que pueda suscitar esta etapa:

"La teoría de la arquitectura en Norteamérica durante estos años ha sido muy poco estudiada y apreciada, y, de 
hecho, a este período frecuentemente se le caracteriza como de escasa innovación y carente de debates arquitectónicos serios. En cambio, los documentos del momento cuentan una historia muy diferente. La literatura crítica en relación a la práctica de la arquitectura en los años de postguerra, excede con mucho, tanto en cantidad como en sofisticación, a cualquier otra producida en un periodo comparable anterior a la guerra. Más aún, gran parte de lo que empezó siendo la teoría europea, fue asimilada y transformada por los debates americanos, indudablemente avivados con la inmigración de arquitectos e intelectuales europeos a este país". (Mallgrave 2005: 326-327)

Es importante anotar el hecho de que durante décadas, estos textos ejercieron una influencia determinante en el curso de la arquitectura -y, en efecto, la siguen ejerciendo-, desde el mismo momento en el que muchos de ellos se siguen publicando, reeditando y traduciendo a varios idiomas. Las interpretaciones, descripciones o genealogías que proponen de los distintos temas que tratan, casi todos ellos en torno al mismo Movimiento Moderno (tanto en su adhesión como en su crítica), ofrecen unas versiones con unos discursos bien diferentes en algunas ocasiones, en función de sus posiciones respecto de la sociedad, la historia, el arte, la arquitectura o las tradiciones, por ejemplo. Quizás por ello se deba reconocer, al menos, un número plural de narrativas sobre un mismo conjunto de acontecimientos: la arquitectura moderna (de entonces). Una lectura atenta de estos presupuestos podría revelar los cambios latentes en algo asumido aparentemente estable y definido (el Movimiento Moderno), al mismo tiempo que ayudaría a entender las maneras en las que algunos textos y muchos edificios se recibieron, se transmitieron y se promocionaron o sancionaron.

Por tanto, este trabajo se centrará predominantemente en los textos, no tanto en las obras construidas o proyectadas; sí, quizás, en los términos en los que dichas obras eran publicadas, comentadas o reseñadas. Entre otras cosas, porque el protagonismo que adquirieron algunos medios, sobre todo ciertas revistas asociadas a organismos poderosos, coaccionó o forzó determinadas situaciones, haciendo que el gesto de opinar -o discutir- con libertad fuese un acto verdaderamente valiente $\mathrm{y}$ arriesgado, tal y como Albert Bush-Brown exponia en 1959:

"El miedo a la represalia existe también en el periodismo arquitectónico, donde unas pocas revistas especializadas, financiadas por la publicidad, se dedican, primero, a divulgar la obra maestra del mes' y, segundo, a mejorar la práctica profesional. [...] A la vista de los resultados, los artículos críticos han aparecido más frecuentemente de lo que generalmente se supone [...] Pero sólo a partir de 1950, llegaron todo un conjunto de críticas, justo después de que Nowicki retara la incorrecta interpretación de la fórmula sullivanesca bajo el dictado de que la forma sigue a la función', al tiempo que Lewis Mumford, John Burchard, Robin Boyd y Paul Rudolph habian instado a los arquitectos [a abrirse] hacia unos postulados más adecuados". (Bush-Brown 1959: 147)

La reacción, natural por otra parte, no se haria esperar:

"Otra respuesta a la crisis profesional de la arquitectura moderna fue el florecimiento de la literatura teórica al establecerse nuevas revistas independientes y académicas. Libres de ataduras a instituciones profesionales, como el American Institute of Architects [A.I.A.], estas revistas a menudo tomaron posiciones críticas frente a las revistas oficiales. [...] Además de estas publicaciones comerciales, proliferaron las revistas asociadas a las universidades $[. .$.$] ; algunas a semejanza de la$ revista 'Perspecta: The Yale Architectural Journal', que data de 1952. [...] Los temas de estas revistas ayudan a delinear las preocupaciones del momento. [...] La seriedad con la que son abordados los contenidos (la historia, la ciudad, la monumentalidad, el paisaje, la tectónica, la ética, etc.) por los alumnos editores y los profesores consejeros, indica la profundidad de la percepción de la crisis". (Nesbitt 1996: 2324)

Si bien muchas de estas cuestiones han sido particularmente incorporadas en algunas historias de la arquitectura moderna recientes (como por ejemplo en los textos publicados por Harry Francis Mallgrave en 2005 o Gwendolyn Wright en 2008), así como en estudios monográficos centrados en asuntos o autores de estos mismos años (es el caso de Ron Robin y sus Enclaves de América en 1992, Meredith Clausen y su monográfico sobre la figura de Piertro Belluschi: arquitecto moderno americano en 1996, o el ensayo de Jane Loeffler sobre el programa de las embajadas de EE. UU. a mediados del siglo XX Arquitectura de la diplomacia en 1998, entre otros), lo cierto es que en realidad parece que han sido abordadas de una manera muy somera, y sin prácticamente ninguna vinculación con el devenir de la 
arquitectura que sobrevendría a comienzos de los años sesenta en Norteamérica.

Por esta razón, aquí se tratará de analizar un conjunto de textos que podrian proponer nuevas interpretaciones de una arquitectura casi contemporánea, reflejo de aquellos años, rellenando, también, parte de un hueco que ha permanecido casi vacío en muchas de las historias que se han escrito de la arquitectura moderna. No obstante, no se pretende reescribir la historia, sino solamente examinar el discurso de algunos de sus autores u observadores que, en palabras de Michel Foucault, son una "práctica discursiva que sistemáticamente forma los objetos de los cuales habla". (Foucault 1972 (1969): 49)

De este modo se ha desarrollado un método historiográfico-periodístico capaz de relacionar las historias o cursos de ciertas ideas o nociones arquitectónicas, dentro de un contexto general (por razones obvias de extensión y formato de este texto). De este modo, si bien se ha llevado a cabo un rastreo minucioso y exhaustivo de fuentes originales, aquí se recogerán solamente aquéllas que parece que tuvieron una repercusión mayor de acuerdo a los objetivos que aquí se quieren tratar: fundamentalmente, una modesta reivindicación de las posibles aportaciones genuinamente norteamericanas a la modernidad arquitectónica.

Por consiguiente, el argumento se abordará como un análisis de dichos textos, seguido por el esfuerzo de generar una síntesis orientada a argumentar la comprensión teórica de los objetivos propuestos. En este sentido, se han empleado dos criterios generales para la selección de las fuentes originales: por un lado, el grado en el que dichos textos son representativos de su contenido (y, por tanto, de su alcance); y por otro, las intenciones de sus autores (tratando de evitar textos ideológicos partidistas o pancartistas, siempre más tendenciosos).

Obviamente, se echará mano de la pluma de Sigfried Giedion, Henry-Russell Hitchcock, Vincent Scully, Lewis Mumford y otros autores similares asentados, pero quizás sobra el decir que ellos no cubren todas las interpretaciones de una arquitectura puesta en tela de juicio. Por ello, se ha querido recoger la voz de aquellos que también ejercian la profesión desde posiciones más humildes o menos elitistas -y no por ello menos importantes-, presentes en multitud de artículos publicados en las páginas de Architectural Record,
Architectural Forum, Progressive Architecture, House Beautiful, etc.

Por otro lado, tampoco se pasará por alto el efecto que tuvo la presencia de los emigrados europeos en los Estados Unidos, que había generado una serie de ideas contradictorias. Mientras que la presencia de Gropius en Harvard y de Mies en Chicago tuvo un reflejo directo en los desarrollos americanos, las teorías europeas, en cambio, tuvieron que ser modificada por el nuevo contexto social, tecnológico y político del país.

Otro de los factores apenas valorado -y que aquí se recoge- es el hecho de que durante estos años se dio una gran multitud de interpretaciones regionales -o "regionalistas"- del Movimiento Moderno. Este regionalismo que terminaría por reconocerse abiertamente, también cuestionó la misma importancia del Estilo Internacional. En este sentido, de acuerdo a la experiencia regionalista, la influencia de la exposición del Museo de Arte Moderno de Nueva York (MoMA) de 1932 y su campaña institucional subyacente ${ }^{3}$ podrian haber acabado teniendo un efecto mucho más débil de lo que se pensó, con la excepción de su demarcación geográfica más próxima (Mallgrave 2005: 327) (figuras 2 y 3).

En efecto, desde mediados de los años cuarenta, parece que se había dado una nueva concepción americana del trabajo y de la noción de hábitat, que había nacido de la Depresión, la guerra y los nuevos valores culturales americanos. Los arquitectos europeos se veían así obligados a reevaluar sus carreras; si bien algunos en un principio no lo comprendieron, también
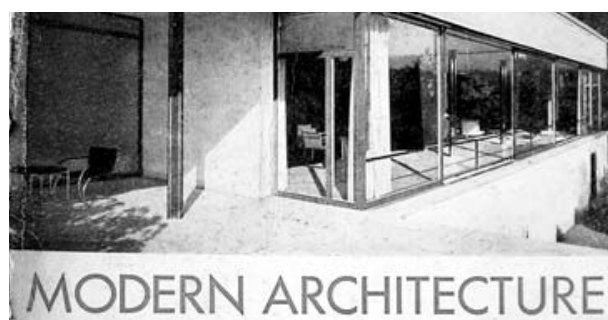

MUSEUM OF MODERN ART 
Figura 3.Portada del libro El estilo internacional: arquitectura desde 1922. 1932. Autores: Henry Russell-Hitchcock y Philip Johnson.

Autor.
THE INTEIENATIONAL STYLE: I ICCIITECTU IRE SINCE I922

BY HENRY.RUSSELL HTCHCOCK, JR, and PHLIP JOHNSON

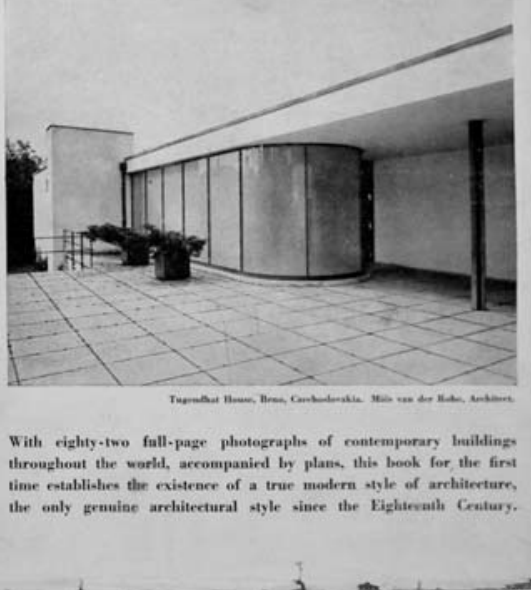

acabaron por adaptarse después. Este proceso de asimilación y adaptación puede verse, incluso, en figuras como la del propio Walter Gropius y algunas de sus obras en los estados de Nueva Inglaterra. ${ }^{4} \mathrm{Se}$ puede apreciar desde el diseño de su propia casa en Lincoln (Massachusetts), de la que luego Sigfried Giedion, en 1954, ya consideraria que su "gran porche frontal" era un excelente ejemplo del "nuevo regionalismo", en contraste con la monotonía del Estilo Internacional (Giedion 1954b: 71) (figura 4).

\section{East versus West}

En términos generales aunque con algunas reservas, se puede decir que a finales de los años cuarenta ya estaba en pleno auge la confrontación entre los arquitectos de los Estados Unidos que pensaban que los europeos habian llevado el Movimiento Moderno a América (al cual se adherian), y los que, en cambio, creían que aquella nación había tenido también su propia modernidad y evolución autóctonas, defendiendo sus formas, materiales y tradiciones (figura 5).

No obstante, los primeros textos al respecto (con un cierto impacto) datan de principios de estos años cuarenta, síntoma de un posible ambiente previo de polémicas y críticas. No sólo se está haciendo referencia aquí al libro de Katherine Morrow Ford $\mathrm{y}$ James Ford (The Modern House in America, 1940) ni al artículo de esta misma autora ("Modern Is Regional", 1941). O incluso al texto previo de Hugh S. Morrison ("After International Style What?", 1940) cuando sugería -quizás de forma prematura- que el Estilo
Internacional habia pasado ya y que en un futuro habria "varios movimientos modernos regionales" (Morrison 1940: 345). Pero es que igualmente, por ejemplo, dentro del propio catálogo de la exposición Built in the U.S.A. que preparó Elizabeth Mock en 1944 para el MoMA, ya en la introducción la autora identificaba las distintas tendencias o corrientes de la arquitectura norteamericana, así como "la sospecha de la 'romantización' de la máquina", "un nuevo interés en la construcción tradicional vernácula” y, más o menos la total asimilación de una evolución a partir de las "formas cerradas y las austeridades indiferentes de los europeos" (Mock 1944: 14). Asimismo, Mock destacaba los trabajos de varios arquitectos locales, anteriores a la llegada de los emigrados europeos, como ejemplares:

"En un principio, [Richard] Neutra estaba más bien solo en sus experimentos con los nuevos tipos de construcción en madera, aunque antes que él, muchos arquitectos [locales] estaban explorando las ilimitadas posibilidades de este material, generando formas nuevas y apropiadas". (Mock 1944: 14) (figura 6)

En este sentido, parece lógico que Neutra protagonizase unos años después la portada de la revista -conservadora- Time, donde se alababa su presunto liderazgo en un movimiento dispuesto a "humanizar y domesticar" el Estilo Internacional (Neutra is 'Man of the Year'. 1949: 2) (figura 7).

De manera similar, Jean Murray Bangs publicaba un artículo polémico en Architectural Record en 1948 (Bangs 1948) sobre la figura de Bernard Ralph Maybeck (arquitecto asentado en la Costa Oeste), pudiendo todavía apoyar sus ideas con citas de otros artículos de calado 'regionalista' que datan de 1942, de entre los que se destacan las siguientes palabras del crítico Talbot F. Hamlin:

"Donde la vida americana ha desarrollado sus líneas más verdaderas y peculiares -digamos, de una manera rápida, en la Costa del Pacífico-, donde en general las costumbres americanas, distinguidas de aquéllas de Europa, se aceptan con más libertad, está evolucionando un tipo de arquitectura doméstica que quizás podría ser la arquitectura doméstica más avanzada del mundo en la actualidad". (Hamlin 1942: 169) (figuras 8 y 9)

Dejando a un lado la cuestión de si esta arquitectura de la Costa Oeste era la más avanzada del mundo o no en aquellos 
Figura 4. Casa Gropius en Lincoln (Massachusetts). 1938. HABS Ma1228-16. Library of Congress, Prints \& Photographs

Division, MASS, 9LIN, 16-16.

Figura 5. Portada del libro La casa moderna en América. 1940. Autores: Katherine Morrow Ford y James Ford. El autor.

Figura 6. Catálogo de la exposición Construido en EE. UU.: 1932-1944, celebrada en el MoMA de Nueva York en 1944. Autora: Elizabeth Mock. El autor.

Figura 7. Portada de la revista Time. 15 de agosto de 1949. Time Magazine Archives.

Izquierda y derecha. Figura 8. Casa Laing. Harwell Hamilton Harris. Los Ángeles (California). 1935. Flickr.

Derecha- Figura 9. Gardner Acton Dailey y William Wilson Wurster. Casa

Owens. Sausalito (California). 1939. Sturtevant.

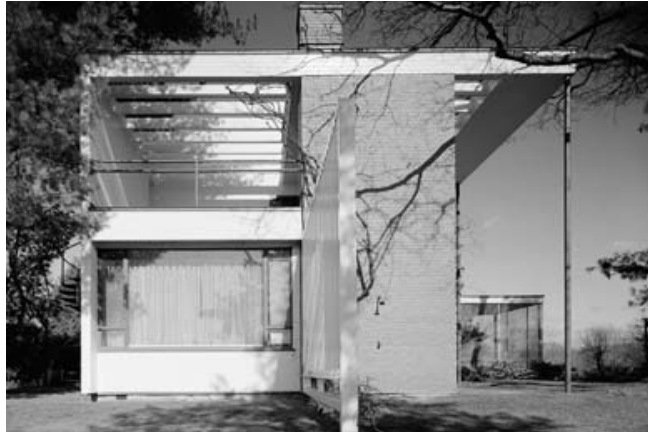

THE MODERN HOUSE IN AMERICA
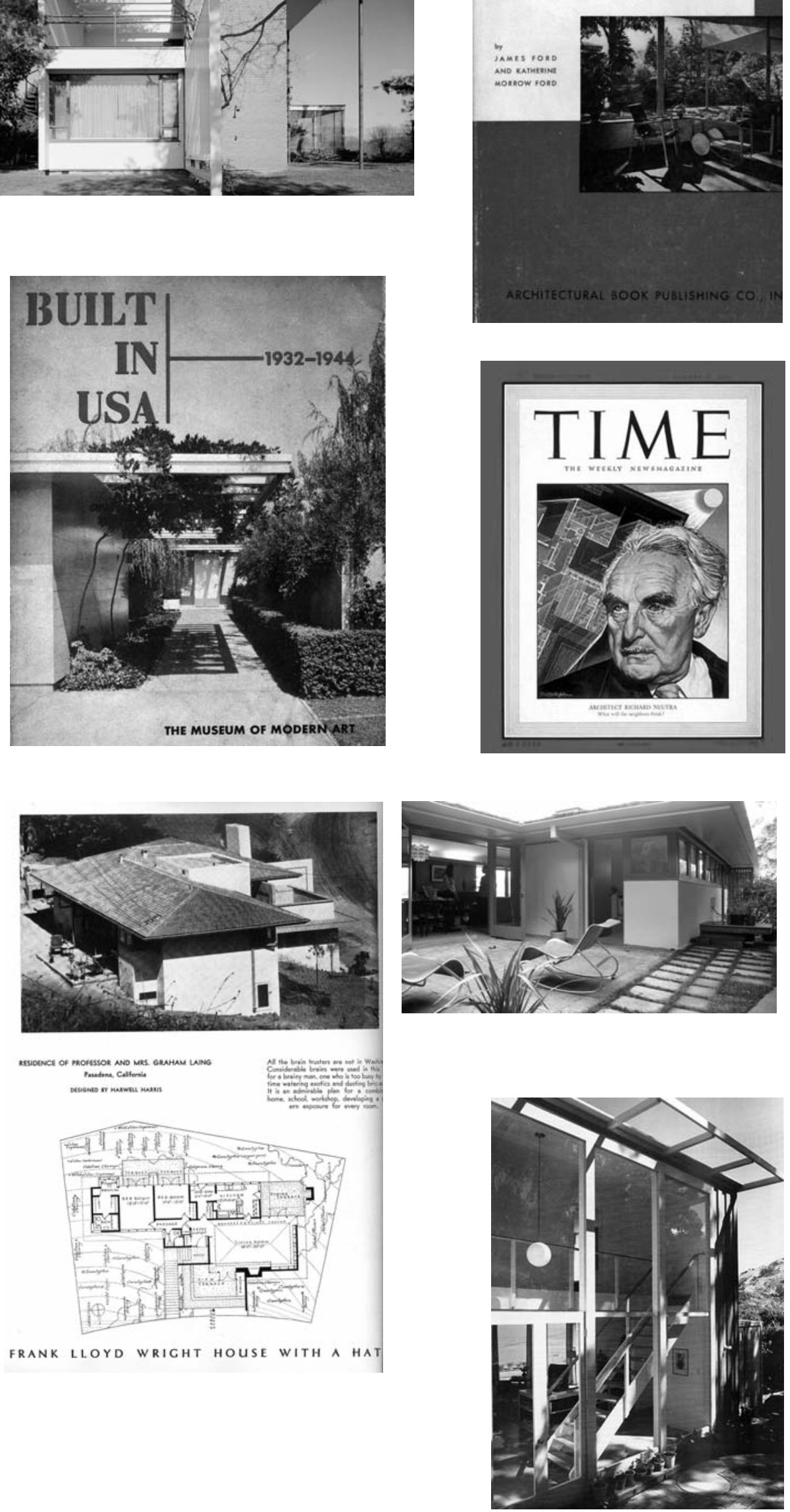


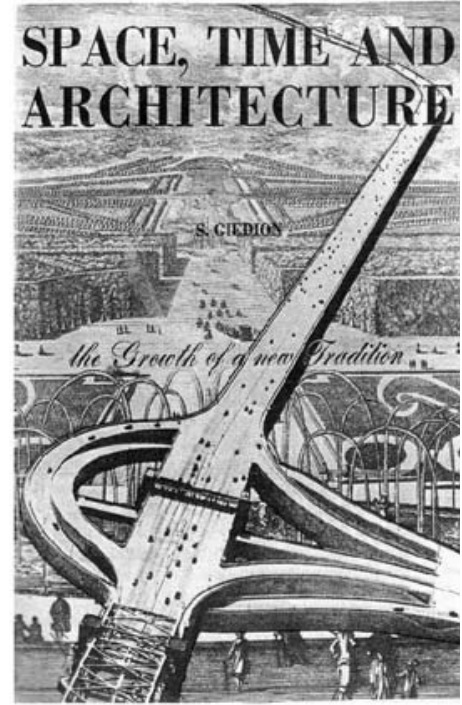

Izquierda. Figura 10. Portada del libro Espacio, tiempo y arquitectura. 1941

Autor: Sigfried Giedion. El autor.

Derecha. Figura 11. Portada del libro Hacia una arquitectura orgánica. 1945. Autor: Bruno Zevi. El autor.

Figura 12. Portada de la revista House Beautiful. Mayo de 1950. El autor. momentos, lo cierto es que se presentaba como una alternativa fuerte frente al Movimiento Moderno importado de Europa. Y en este sentido, empezaban a surgir las diferencias, rivalidades $\mathrm{y} / \mathrm{o}$ adhesiones a uno $\mathrm{u}$ otro de los dos "bandos": por un lado, el "moderno ortodoxo" del Este y, por el otro, el" moderno regionalista" del Oeste. Sin embargo, Wayne Andrews había ido más allá de esta situación cuando un año antes había sentenciado:

"La batalla del siglo xx [...] no está en si debemos construir según el Movimiento Moderno o a la manera tradicional, sino más bien en qué tipo de Movimiento Moderno. A pesar de que una encuesta realizada a unos cien arquitectos pueda dar la impresión a un observador inocente de que no hay menos de cien variedades de arquitectura americana, lo cierto es que no hay más que dos marcas promocionadas por los arquitectos en nuestra generación". (Andrews 1947: 252)

Es preciso aclarar que Andrews se estaba refiriendo fundamentalmente a la diferencia entre los arquitectos denominados "veblenianos" (que según Thorstein Veblen "condenaban la expresión sin límites del individualismo en toda forma") y los "jacobianos" (siguiendo a William James cuando éste creyó ver en las "diferencias entre los distintos individuos, el centro de la cuestión”), (Andrews 1947: 252). En otras palabras, de alguna manera Andrews también había empezado a plantear el problema de la libertad formal del arquitecto frente a la norma (o la moda).

Por otra parte, estos autores no son los únicos que habian tratado de establecer o aclarar las discrepancias entre las posi-

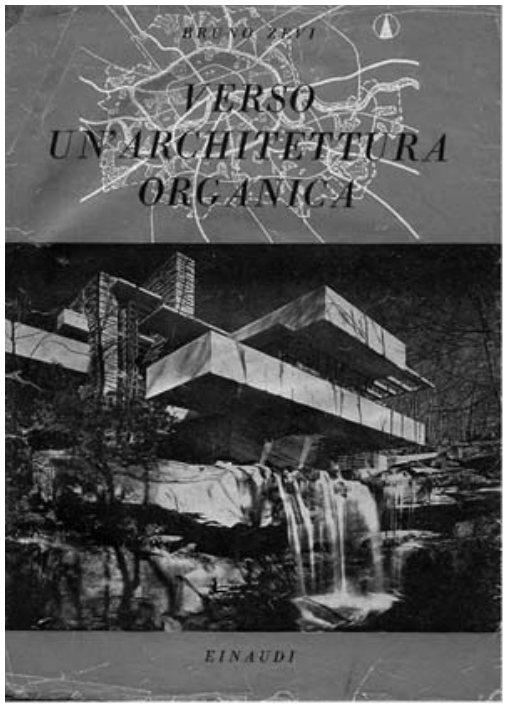

bles actitudes o alternativas arquitectónicas a la modernidad más difundida (esto es, el Estilo Internacional). Ya en 1945, Bruno Zevi había publicado su libro Hacia una arquitectura orgánica (Zevi 1945) en Turín, donde respondía al manifiesto de Sigfried Giedion (Espacio, Tiempo y Arquitectura de 1941) con una fuerte argumentación a favor de la arquitectura orgánica, dejando claro que ésta, aun siendo moderna, se diferenciaba del Estilo Internacional porque en ella era "el espacio el protagonista de la arquitectura" y no "la masa" (Zevi 1945: 105-106). El debate no se agotaría a corto plazo, pues varios años más tarde -en 1961- Vincent Scully seguiría distinguiendo entre un Movimiento Moderno "clásico" y otro "romántico" (Scully 1961: 15) (aunque poco tiempo después, en 1965, terminaría por explicar que ambos, en el fondo, eran una misma cosa (Scully 1965: 36-37) (figuras 10 y 11).

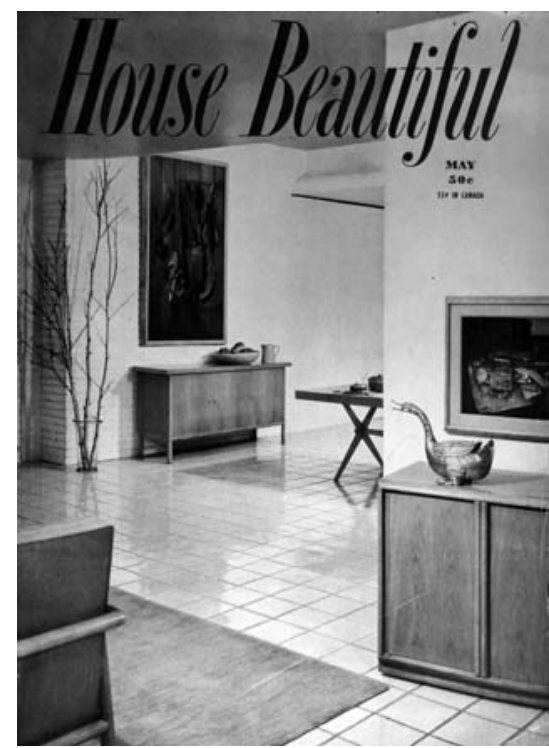



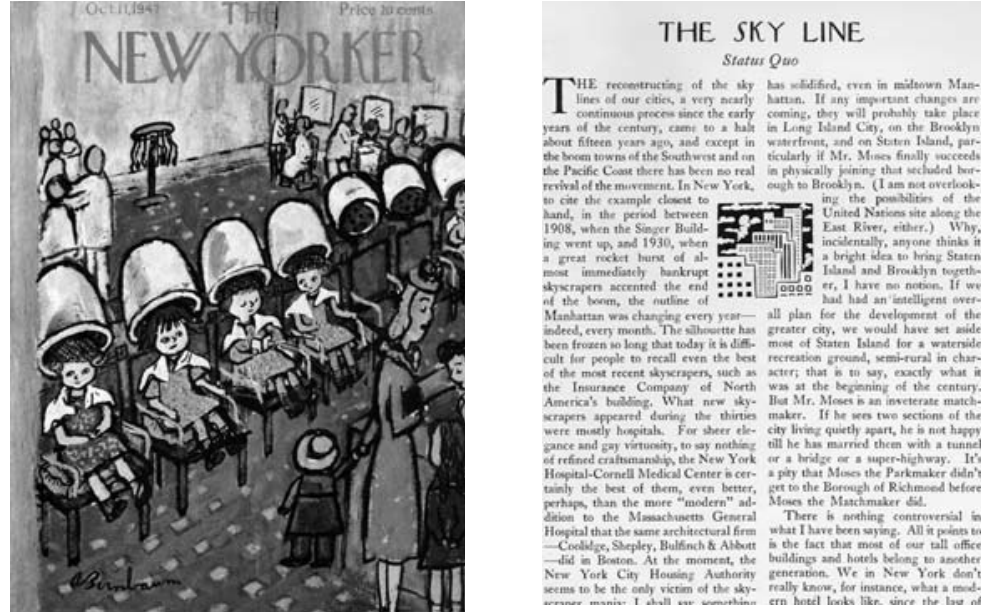

Izquierda. Figura 13 Portada de la revista The New Yorker. 11 de octubre de 1947. The New Yorker magazine archives.

Izquierda. Figura 14. Columna "The Sky Line. Status Quo". The New Yorker. 11 de octubre de 1947 Autor: Lewis Mumford. The New Yorker magazine archives.
Sin embargo, probablemente no se pueda encontrar otra figura más polémica en relación a estos debates de finales de los años cuarenta que la de Lewis Mumford. En un principio, Mumford se adhirió a la causa "europeísta" de una manera casi absoluta: en 1931 escribía que tras la Exposición Internacional Colombina de Chicago de 1893, los arquitectos americanos "habian estado, durante cuarenta años, deambulando por el árido desierto del clasicismo y el eclecticismo" (Mumford 1931: 271), colaborando con sus palabras a gestar o promocionar una especie de mitología que rodearía la llegada del Movimiento Moderno a los Estados Unidos. De hecho, Sigfried Giedion se expresaría en unos términos muy pareci dos cuando diez años más tarde sentenciaba:

"Después de la sinceridad estructural de la primera Escuela de Chicago durante los años ochenta, después de la excepcional pureza de la expresión arquitectónica de Louis Sullivan y del emocionante ejemplo de Frank Lloyd Wright hacia el año 1900, el espíritu de la arquitectura americana había degenerado en clasicismo mercantil. [...] El impulso para liberarse de esta desastrosa evolución ha tenido que venir de fuera". (Giedion 1941: 500)

En cambio, como se verá a continuación, a finales de los años cuarenta Mumford se convertía, quizás, en uno de los mayores defensores del valor de la evolución de la propia arquitectura norteamericana hacia una determinada modernidad, vernácula y previa a la llegada de los emigrados europeos. ${ }^{5}$ Junto a él se adscribiría James Marston Fitch firmando un artículo para la revista House Beautiful en 1950 en el que trazaba la evolución de la arquitectura norteamericana durante los setenta años anteriores a su publicación, haciendo un especial hincapié en los precedentes autóctonos del estilo moderno (Fitch 1950). Asimismo, Joseph Hudnut, ya por entonces Decano de la Graduate School of Design de Harvard (GSD), y responsable de la llegada de Gropius a aquella universidad, mostraba su preocupación en 1949 por el temor de que en la arquitectura la "ciencia [i.e., la tecnologia] hubiese reemplazado valores como las buenas maneras, el sentido común y el amor" (Hudnut 1949: 116). Y, como era de esperar, en la Costa Oeste seguian surgiendo figuras alineadas con Mumford y sus simpatizantes, como la del Decano de la Universidad de Berkeley (y luego del Instituto Tecnológico de Massachusetts, MIT), William W. Wurster, que igualmente acabaría convirtiéndose en otro símbolo de la causa regionalista (figura 12).

A fin de cuentas, la defensa de los valores modernos regionales o locales fue un hecho importante que acabó por acaparar gran parte del debate arquitectónico a finales de los años cuarenta, tanto a un lado como al otro del país, generando otras tantas discusiones subyacentes de gran trascendencia con posterioridad, más allá de la defensa de los hechos diferenciales identitarios regionales o tradicionales: aunque de manera muy incipiente, empezaba a tratarse también el problema de la expresión formal de la arquitectura, sus valores culturales, sus simbolos, etc.

\section{East plus West}

Exactamente cuatro meses después -y como consecuencia- de que Lewis Mumford publicase una columna titulada The Sky Line. Status Quo en la revista The New Yorker (Mumford 1947), en octubre de 1947, dedicada a la arquitectura del "Estilo de la Bahía [Californiana]", el Museo de Arte Moderno de Nueva York (MoMA) organizaba un simposio el 11 de febrero de 1948. Su título era precisamente un claro reflejo de la situación de caos y desencuentros entre los protagonistas y los presupuestos o principios de la arquitectura moderna norteamericana de mediados del siglo XX: What is Happening to Modern Architecture? (¿Qué le está pasando a la arquitectura moderna?) (Barr et al. 1948). El evento consiguió atraer una gran participación de arquitectos, incluyendo los nombres de Walter Gropius, Marcel Breuer, Sergei Chermayeff, Edgar Kaufmann Jr., Matthew Nowicki, Eero Saarinen, Vincent Scully..., además de los organizadores del museo: Alfred H. Barr, Henry-Russell Hitchcock y Philip Johnson (figuras 13 y 14). 
Figura 15. Portada del Bulletin of the Museum of Modern Art. Nueva York. Primavera de 1948. (Barr et al. 1948: 1).

Figura 16. Panel de ponentes del simposio del Moma de febrero de 1948. (Barr et al. 1948: 3).

Figura 17. Catálogo de la exposición Arquitectura doméstica de la región de la Bahía de San Francisco (Mumford et al. 1949). El autor
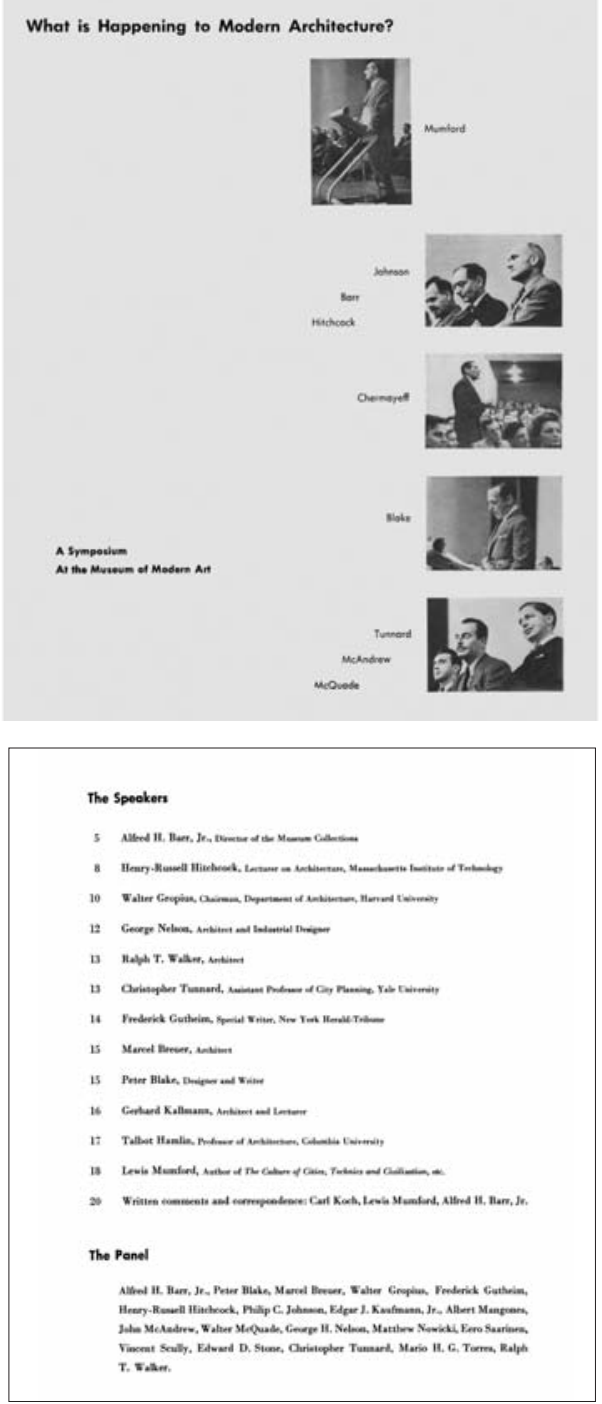

Sin embargo, las respuestas ofrecidas a una pregunta tan ambiciosa y controvertida no fueron fáciles ni satisfactorias para casi ninguno de los asistentes: "Como simposio formal, el evento fracasó" (Barr et al. 1948: 4). No se llegó a ninguna conclusión y la pregunta quedó sin resolverse. Por el contrario, la conferencia fue un éxito como catálogo y puesta en común de una serie de ideas y posiciones diversas y conflictivas, si bien a la vez estimulantes para el debate (figuras 15 y 16).

Aunque el simposio del MoMA no aportase demasiada luz al problema de la arquitectura moderna, sin embargo sí tuvo una gran influencia en su público y también en varias publicaciones, incluso del noreste del país donde las posiciones en defensa de la arquitectura moderna importada parecian estar más afianzadas: por ejemplo, Joseph Hudnut desde Harvard (bastión de los arquitectos más fieles al Movimiento Moderno) decidió reeditar su texto The Post-Modern House (La casa post-moderna) (Hudnut 1945) de 1945, publicándolo de nuevo en 1949 (Hudnut 1949), posicionándose en contra de la arquitectura "de la línea de montaje", de la "arquitectura hecha en serie de las casas de Gropius", e insistiendo en el "equilibrio entre los valores emocionales y la tecnologia” (Hudnut 1949: 118-119).

Además de ésta y otras muchas criticas en contra del Estilo Internacional, de una manera un tanto generalizada empezaba ya a exacerbarse una sensibilidad especial hacia la herencia cultural y formal propiamente (o típicamente) norteamericana, una identidad inherente en aquellas formas vernáculas o "no estrictamente arquitectónicas", con lo que el estudio y difusión de las tradiciones o rasgos caracterizadores de los edificios históricos estadounidenses se convertía en uno de los temas recurrentes de la arquitectura de este país, especialmente a partir de la década de los años cincuenta. Así, en este mismo año de 1949, el National Council for Historic Sites and Buildings (Consejo Nacional de Lugares y Edificios Históricos) pasaba a denominarse National Trust for Historic Preservation (Administración Nacional para la Conservación del Patrimonio Histórico), y, por vez primera, el Museo de Arte Moderno de San Francisco (SFMoMA) organizaba una exposición a finales de este mismo año dedicada íntegramente a la arquitectura moderna vernácula de esta ciudad, titulada Domestic Architecture of the San Francisco Bay Region (Arquitectura doméstica de la región de la Bahía de San Francisco) (Mumford et al. 1949), con la participación de Lewis Mumford y William W.Wurster (entre otros autores) (figura 17).

Como se puede ver, el choque entre la estética y principios del Estilo Internacional y las diferentes tendencias locales de muchas regiones de los Estados Unidos era ya un hecho -cada vez más preocu-

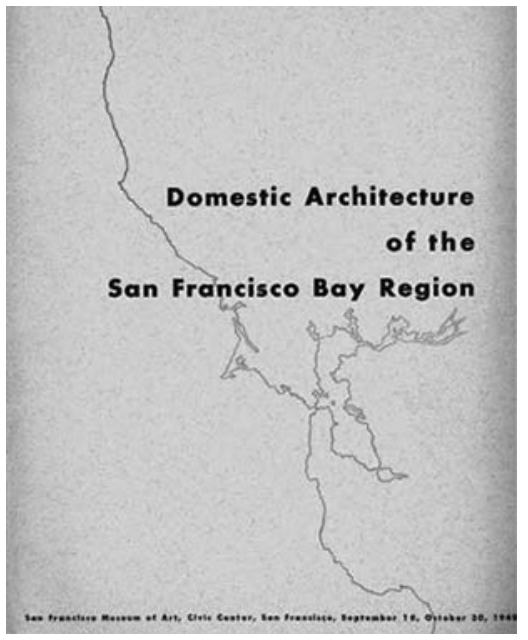


Figura 18. Artículo "El Estilo Internacional veinte años después" (Hitchcock 1951) El autor

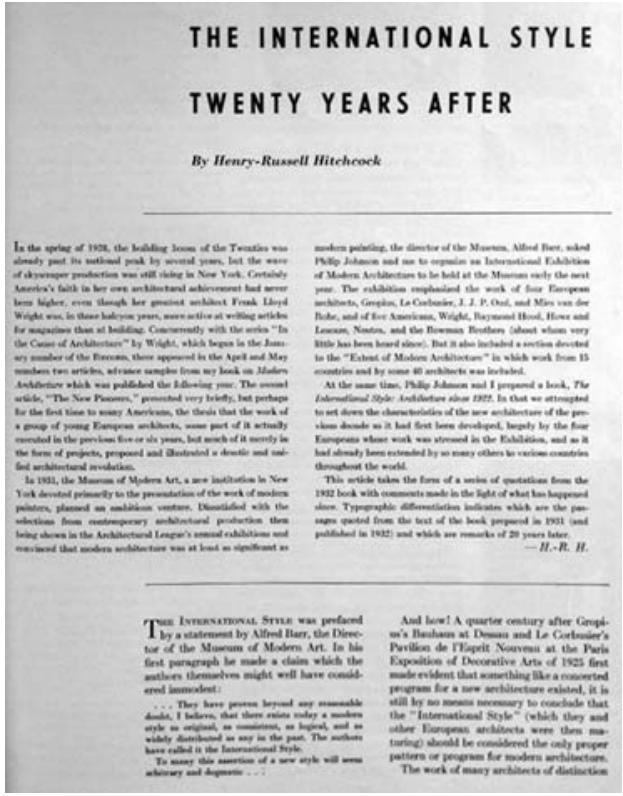

pante, por otro lado- tanto para profesionales como críticos: entre dichas posturas ya había incompatibilidades prácticamente insalvables (tal y como se puede comprobar en las actas del simposio del MoMA del año 1948), pero sobre todo desde comienzos de 1951 cuando Ralph T. Walker (entonces Presidente del Instituto Americano de Arquitectos, A.I.A.) publicaba un polémico artículo en el Journal of the American Institute of Architects (Walker 1951), en el que llegaba poco menos que a denigrar a los arquitectos europeos exiliados en los Estados Unidos por empobrecer la arquitectura norteamericana. Asimismo, aunque sin llegar a tales extremos, en aquel mismo volumen de febrero de 1951, Pietro Belluschi tomaba posiciones cercanas a las de Walker en el artículo "Arquitectura y sociedad" (Belluschi 1951), donde denunciaba el hecho de que la sociedad se había "condicionado por la máquina", que la arquitectura había "perdido su consideración hacia el clima y el contexto" y que el "arquitecto moderno tiene que llegar a un acuerdo con el entorno". Si bien celebraba lo que describía como el "asesinato del dragón del BeauxArts", en cambio lamentaba la pérdida de los valores emocionales y el nefasto dogmatismo intolerante hacia los "símbolos y las formas del pasado" por parte de los arquitectos del Estilo Internacional.

Seis meses más tarde de la citada publicación del A.I.A., el propio Henry-Russell Hitchcock en Architectural Record también se desdecía de parte del discurso defendido en 1932, al poner ahora en tela de juicio la "arquitectura del funcionalismo". Más aún, en gran medida estimaba que ese funcionalismo frío era la imagen de lo que al final se había venido a reconocer como Estilo Internacional. En consecuencia, predecía el advenimiento de un "período tardio" en dicho estilo, reducido entonces a la "repetición académica de fórmulas normalizadas y a la reacción en contra de los principios del estilo" (Hitchcock 1951: 89-90) (figura 18).

De esta manera, da la sensación de que la primera mitad de la década de los años cincuenta se había constituido como el campo de batalla más duro visto hasta el momento entre los defensores de la arquitectura importada de Europa y los que defendian la ya considerada como "verdadera" arquitectura moderna norteamericana. En este sentido, el año 1953 resultaba especialmente polémico, sobre todo tras la publicación de un artículo caracteristicamente irritante, titulado "The Threat to the Next America" ("La amenaza a la América próxima") firmado por Elizabeth Gordon (Gordon 1953), Directora a la sazón de la revista House Beautiful. En dicho artículo, Gordon señalaba directamente y sin cortapisas la amenaza que suponían "algunos museos, algunas revistas profesionales, algunas escuelas de arquitectura y algunos arquitectos" por atormentar y fustigar al público con el eslogan de que "menos es más". Para la autora, esta definición de arquitectura y diseño modernos, que promovía la universalidad, el vacío desvalijado, la falta de espacio de almacenamiento $\mathrm{y}$, por tanto, de pertenencias, era contraria al sentido común y claramente "mala". ${ }^{6}$ Así, "los arquitectos del Estilo Internacional sólo representan una rama más del Movimiento Moderno, totalmente ajena a las raíces americanas". Contraponía el "individualismo" de algunos arquitectos americanos, como Wright, con aquellos arquitectos autodenominados "árbitros del buen gusto" que continuamente bailaban al ritmo de las últimas modas de Europa. Denunciaba "los fraudes, los plagios sobre-publicitados y las tácticas de intimidación de los auto-elegidos como élite que dictan no sólo el buen gusto, sino todo un modo de vida" (Gordon 1953: 126-127). Por el contrario, mantenía que era mucho más sana:

"La rama del estilo moderno autóctono, una variedad nuestra del diseño moderno, que se ha desarrollado sobre principios funcionales a lo largo de los últimos sesenta años, y que está en un buen momento. Esta tendencia, sana y racional, está más que dotada para producir edificios que sean tanto bellos como funcionales, sin sacrificar ninguno de los dos objetivos" (Gordon 1953: 127) (figuras 19 - 23). 
Figura 19.

Portada de la revista House Beautiful. Abril de 1953. El

autor.

Figura 20. Articulo "La amenaza a la América próxima" (Gordon 1953: 126). El autor.
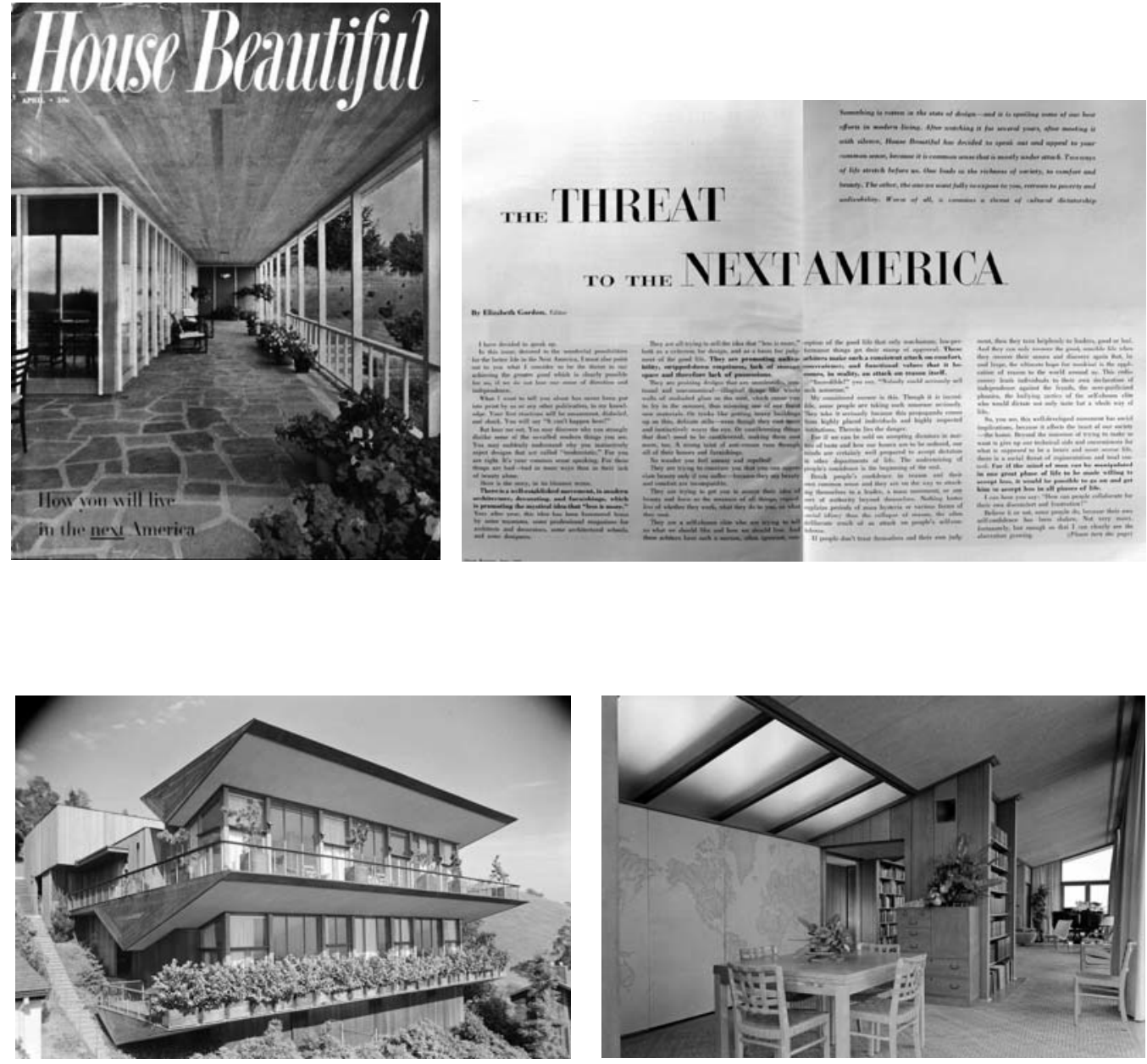

Figura 21. Arriba izqda.: Embajada de EE. UU. en

Yokohama (1932) Arriba dcha.

Embajada de EE. UU. en Ottawa (1931)

Abajo izda.:

Embajda de EE

UU. en Rio de

Janeiro (1953)

Abajo centro:

Embajada de EE.

UU. en La

Habana (1952)

Abajo dcha.

Embajada de EE.

UU. en Madrid

(1954).

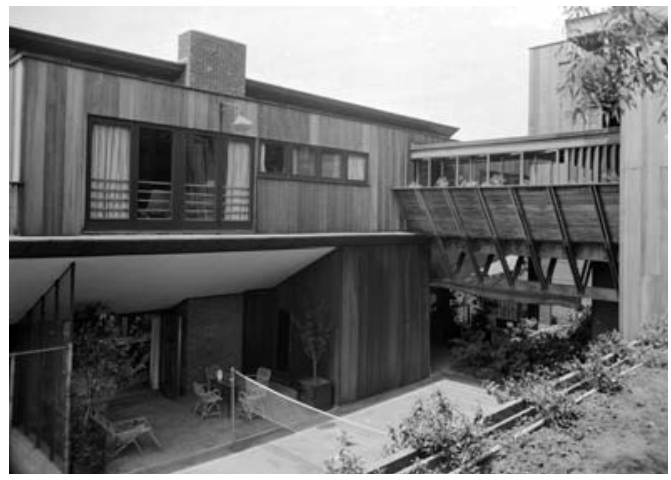

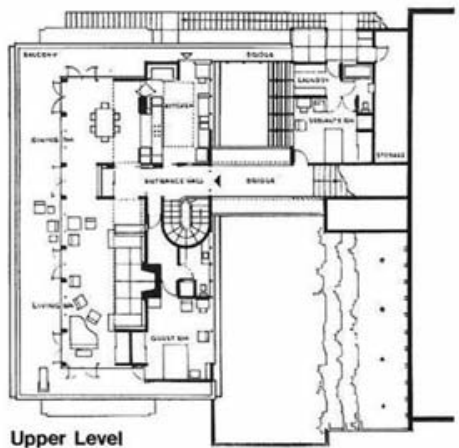

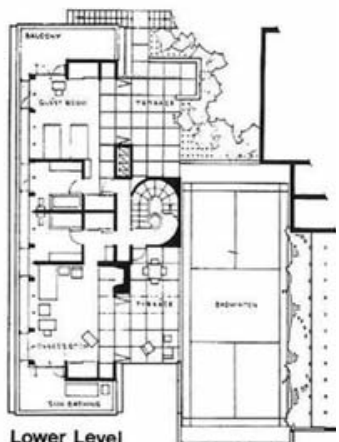


Figura 22. Gordon Drake. Casa del arquitecto (San Francisco, 1945). Foto: Julius

Schulman. The J. Paul Getty Research Institute. Los Ángeles.

Figuras 23. Casa Unit, Gordon Drake. (San Francisco, 1949). Vistas y plan tas. Fotos: Julius Schulman. Progressive Architecture Archives.

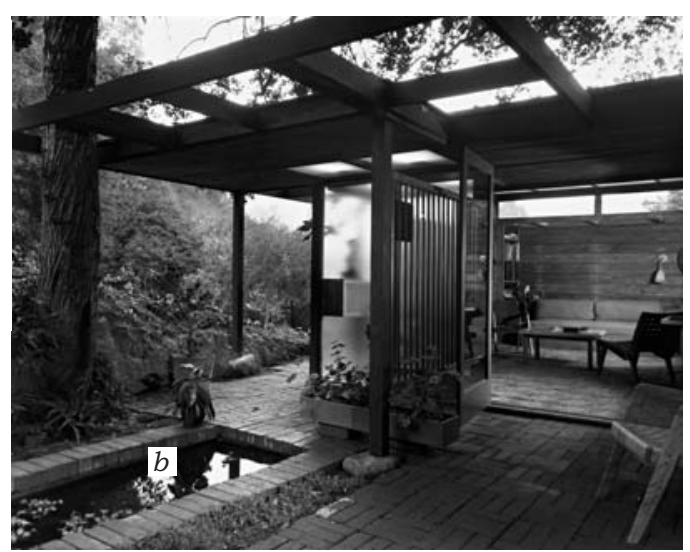

No satisfecha con la mera publicación de su artículo, Gordon decidió enviar un ejemplar de la revista a todos los editores de las principales publicaciones arquitectónicas de Nueva York. Muchos de ellos la criticaron por sus anhelos "chovinistas, pancartistas y nacionalistas" (Creighton
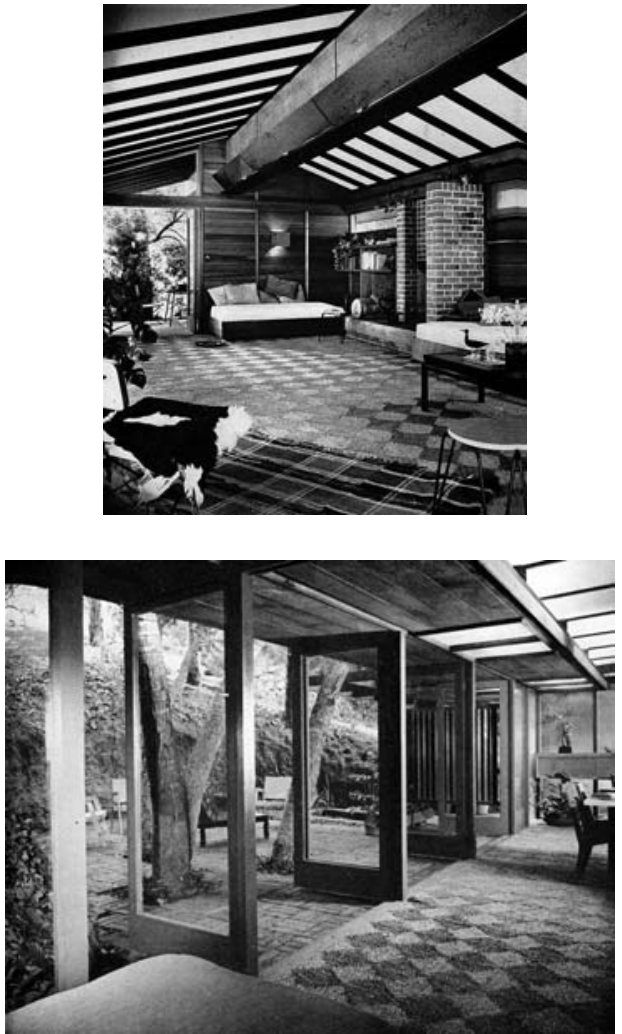

1953: 234), si bien parece que ninguno supo ver el problema que a ella más le enfurecia: la aceptación acrítica del Estilo Internacional por parte de la mayoría de dichas publicaciones neoyorquinas, que además actuaban como coercitivos agentes de poder y de estilo. De todas aquellas publicaciones, tan sólo Architectural Record, quizás la revista más afín a las posiciones de Gordon, acabó dedicando su número de finales de abril de 1953 a la arquitectura del "Pacífico Noroeste" (Architecture of the Northwest. Northwest Houses. 1953). Es posible que esto se deba a la coincidencia temporal con el anuncio de la Convención Anual del A.I.A. que se celebraría los días 15-19 de junio de ese mismo año en la ciudad de Seattle, cuyo emplazamiento ya anunciaba de alguna manera su tema principal: el debate sobre valor de la arquitectura norteamericana regionalista $\mathrm{y}$, en especial, la importancia de la escuela de la Bahía de San Francisco.

Sin embargo, el debate generado, previo a dicha convención, había avivado las diatribas públicas en la prensa escrita todavía más, y fomentó la aparición de algunos textos críticos más en relación a estas cuestiones. Así, en mayo de 1953 Architectural Forum lanzaba una serie de artículos que estimulaban la reflexión sobre la validez de las distintas opciones y tendencias de la arquitectura moderna de entonces, algunos de ellos firmados por personajes notables (figura 24).

Por ejemplo, el primero (publicado en julio de ese mismo año) lo firmaba Eero Saarinen, que aprovechaba la ocasión para identificar las que -según él- eran las principales tendencias del estilo moderno en aquel momento en los Estados Unidos, codificando los rasgos estilísticos de las seis principales ramas o tendencias de la arquitectura moderna norteamericana. En general, mantenía la distinción entre el grupo de arquitectos del Oeste, encabezado por Pietro Belluschi y William W. Wurster ("un grupo fuerte de individuos

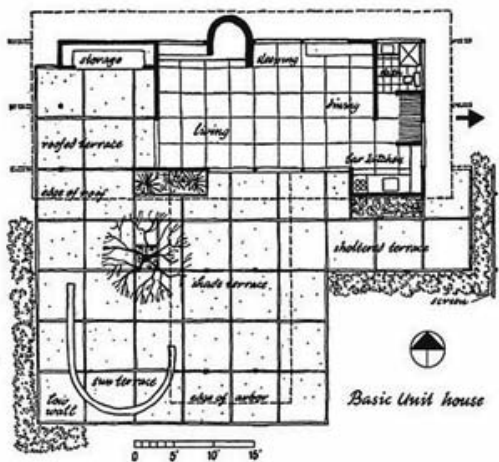

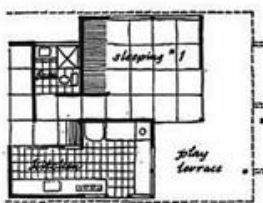

one Gedroom adition

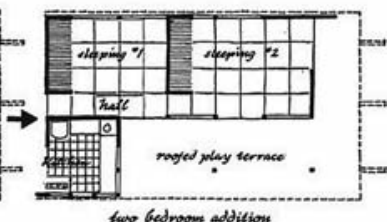


Figura 24.

Fragmento de la portada de la revista Architectural Forum. Julio de 1953. El autor.

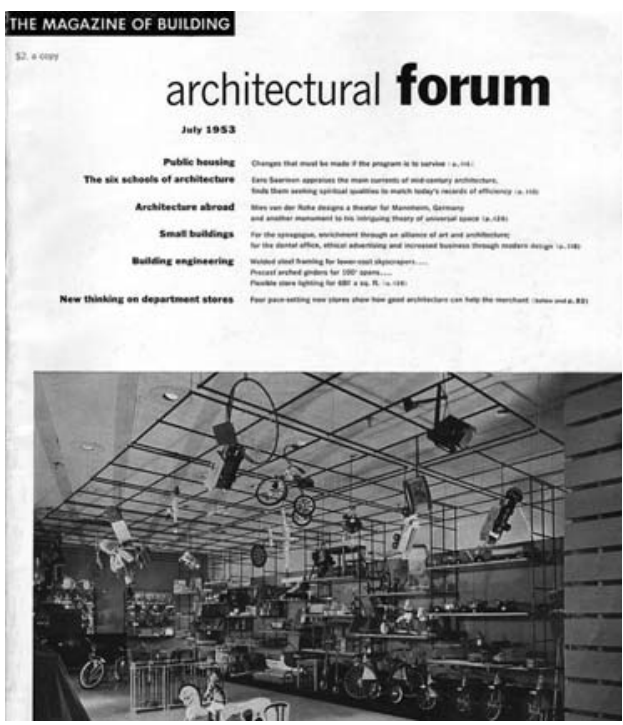

que buscan sus propias formas en la arquitectura mediante una particular responsabilidad sobre el problema impuesto de las condiciones regionales o locales y las tradiciones"), a los que veía como arquitectos "con los pies en el suelo, atentos a las cuestiones humanísticas" aunque con "una tendencia desenfrenada hacia lo emotivo o sentimental, careciendo de una disciplina artística o estructural, por lo que tienen poco futuro" (Saarinen 1953: 111). En el bando opuesto situaba a los "funcionalistas": Le Corbusier, Walter Gropius y Mies van der Rohe, seguidos por el resto de arquitectos acólitos del Estilo Internacional.

El segundo artículo (publicado en septiembre de 1953) venía de la pluma de Robert Woods Kennedy, con un título prestado de otro artículo previo de Hugh Morrison (ya mencionado anteriormente, Morrison 1940): "Después del Estilo Internacional, entonces ¿qué?”. Kennedy señalaba que el Estilo Internacional se había convertido en algo tan académico y pasado de moda como la arquitectura de los "revival". Veía una interpretación más humana del Movimiento Moderno en las propuestas de los regionalistas de la zona de la Bahía (de San Francisco), a los que ya consideraba como sucesores del estilo del MoMA, fundamentalmente por su "sentido común, por ser contrarios a las normas, a los estilos, a los dogmas y su despreocupación por la [estética de la] técnica" (Kennedy 1953: 130).

En cuanto a la Convención Anual del A.I.A. de Seattle de este mismo 1953, cabe destacar la participación de Pietro Belluschi (entonces Decano del M.I.T. desde 1951), cuya conferencia se centraba, por vez primera entre los ponentes, más en cuestio- nes teóricas que formales, yendo un paso más lejos de las meras clasificaciones de tendencias o codificaciones de invariantes autóctonos; su título "El espíritu de la nueva arquitectura" hacía referencia al libro de Le Corbusier (Hacia una arquitectura, 1923) y a las primeras etapas de pensamiento del Movimiento Moderno anteriores a su sistematización formal y estilística. Por ello, no quiso mostrar diapositivas al público, evitando "las cuestiones superficiales y de modas, que han seducido, atraído o irritado los ojos de nuestras revistas"”. Su objetivo, en cambio, eran los principios fundamentales del hecho moderno: recordaba que la arquitectura no era un arte puro en sí mismo, pues debia cumplir con muchos requisitos y obligaciones prácticas, si bien reconocia que un aspecto capital del Movimiento Moderno había sido el "esfuerzo de unos pocos arquitectos-artistas" para generar lo que denominaba como "los nuevos símbolos estéticos"” de la época. Belluschi ponía de relieve esta cuestión:

"[La sociedad] necesita hombres que puedan ayudar a proporcionar un entendimiento nuevo y más profundo, que puedan ayudar a restaurar la relación entre forma y materia en el espíritu de la poesía, lo cual necesita continuamente de un nuevo lenguaje con el que expresarse". (Belluschi 1953a: 97)

En este sentido, a Belluschi no le preocupaban únicamente los valores de la arquitectura regional de la Costa Oeste del país, sino que, de alguna manera, pretendía abordar lo específico de la arquitectura moderna como una realidad ubicua, extensible a todas las regiones, culturas, climas... Procuraba, más bien, la simbiosis entre las posiciones tanto de los arquitectos del Oeste como también del Este: buscaba una manera de ser moderno sin despreciar los avances de los europeos, y sin renunciar a las propias tradiciones de las arquitecturas locales. Además -y quizás debido a ello-, por estas mismas fechas Belluschi era propuesto para formar parte del Architectural Advisory Committee (Comité Asesor de Arquitectura, AAC), una sección de la Foreign Buildings Operations (Oficina de Operaciones de Edificios Oficiales en el Extranjero, FBO) del Departament of State (Departamento de Estado, DS). ${ }^{7}$ Un hecho que ahora quizás se comprenda mejor puesto que el Gobierno Norteamericano estaba preocupado por generar y defender una imagen de vanguardia -tanto del arte, como de la arquitectura-, propia y genuina de la nación, exportable al extranjero (durante 
la Guerra Fría) al que, además, debía respetar en su contexto.De acuerdo a los estudios llevados a cabo por Jane Loeffler (Loeffler 1998), dado que el papel de propaganda de la arquitectura norteamericana no surtía tanto el efecto deseado con sus exposiciones itinerantes, se decidió que quizás sería más adecuado llevarlo a cabo con el programa de construcción de nuevas embajadas del gobierno estadounidense por todo el mundo. ${ }^{8}$ Desde la fundación de la FBO, la apariencia de sus consulados y embajadas cambió considerablemente con respecto a los anteriores. En general, hasta 1945 casi todas estas obras eran historicistas y un tanto rancias, fruto de unos arquitectos formados en la École des Beaux Arts de París. ${ }^{9}$ Así, las embajadas de Río de Janeiro (1923), México D.F. (1925), Managua (1927), Ottawa (1931), Tokio (1932), Bagdad (1938) y Perú (1944) lucian una imagen neoclásica palladiana o colonial, según los casos.

Sin embargo, recién acabada la Segunda Guerra Mundial, Leland King (primer director de la FBO) impuso unas directrices ligadas al Movimiento Moderno, opuestas al historicismo neoclásico practicado y que también estaba utilizando la política soviética en sus edificios en el extranjero-. Por ello, las nuevas embajadas de Río de Janeiro (1948-1953), Cuba (1950-1952) y Madrid (1952-1954) se despojaron de dichos estilos historicistas, y ahora presentaban una imagen más limpia, aséptica y rotunda, más próxima al Estilo Internacional sintetizado por el MoMA en sus exposiciones y estereotipado en el Edificio de la Organización de las Naciones Unidas de Nueva York, que estuvo en construcción desde 1949 hasta 1952 (figu-

Figura 25. Arriba Embajada de EE. UU. en Ottawa, Canadá (1931); Consulado de EE. UU. Brasil (1948). Abajo: Embajada de EE. UU. en La Habana, Cuba (1950); Embajada de EE. UU. en Madrid, España (en Yokohama, Japón (1932); Embajada de EE. UU. en Río de Janeiro, 1952). ra 25). No obstante, se iniciaron una serie de investigaciones sobre la propia FBO que acabarian afectando también a la propia imagen de la arquitectura: al Congreso le pareció mal el que los edificios de los Estados Unidos de América en el extranjero se pareciesen demasiado a dicho edificio de las Naciones Unidas (Loeffler 1998: 108). La situación se agudizó cuando una serie de arquitectos norteamericanos relevantes criticó este mismo hecho, como por ejemplo Paul Rudolph, Pietro Belluschi, Rudolf Schindler..

Asimismo, la revista Architectural Record consideró que los extractos de la conferencia de Belluschi en Seattle, publicados en agosto de 1953, merecian un desarrollo mucho mayor, por lo que le solicitaron el texto completo de su ponencia para que apareciera en el siguiente número de la revista (Belluschi 1953b). Para suerte de Belluschi (e incluso de la CIA, tal y como sostiene Meredith L. Clausen, por apostar por este punto de vista como el idóneo a la hora de abordar el diseño de los edificios oficiales fuera de las fronteras de EE. UU. (Clausen 1994: 210)) su artículo publicado en octubre de 1953 resultaria premiado como el mejor del año por el A.I.A.

En este sentido y de manera similar, Sigfried Giedion se sumaba al asunto viendo con muy buenos ojos las intenciones de Belluschi. Antes de que este último se marcharse del M.I.T. para unirse al equipo de profesores de Harvard, en enero de 1954 Giedion publicaba un artículo en Architectural Record titulado "El estado de la arquitectura: la aproximación regionalista" (Giedion 1954a), en el que exhortaba a los arquitectos modernos a ir más allá
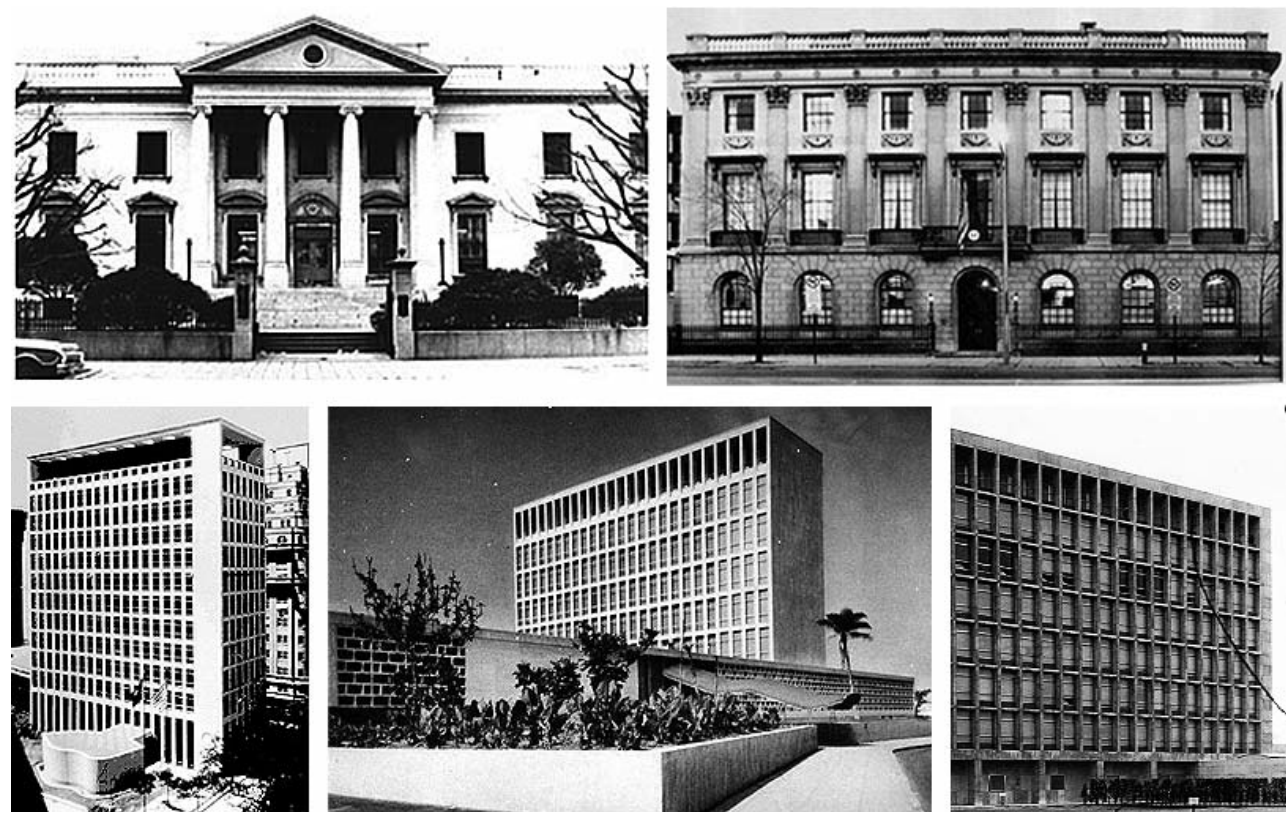


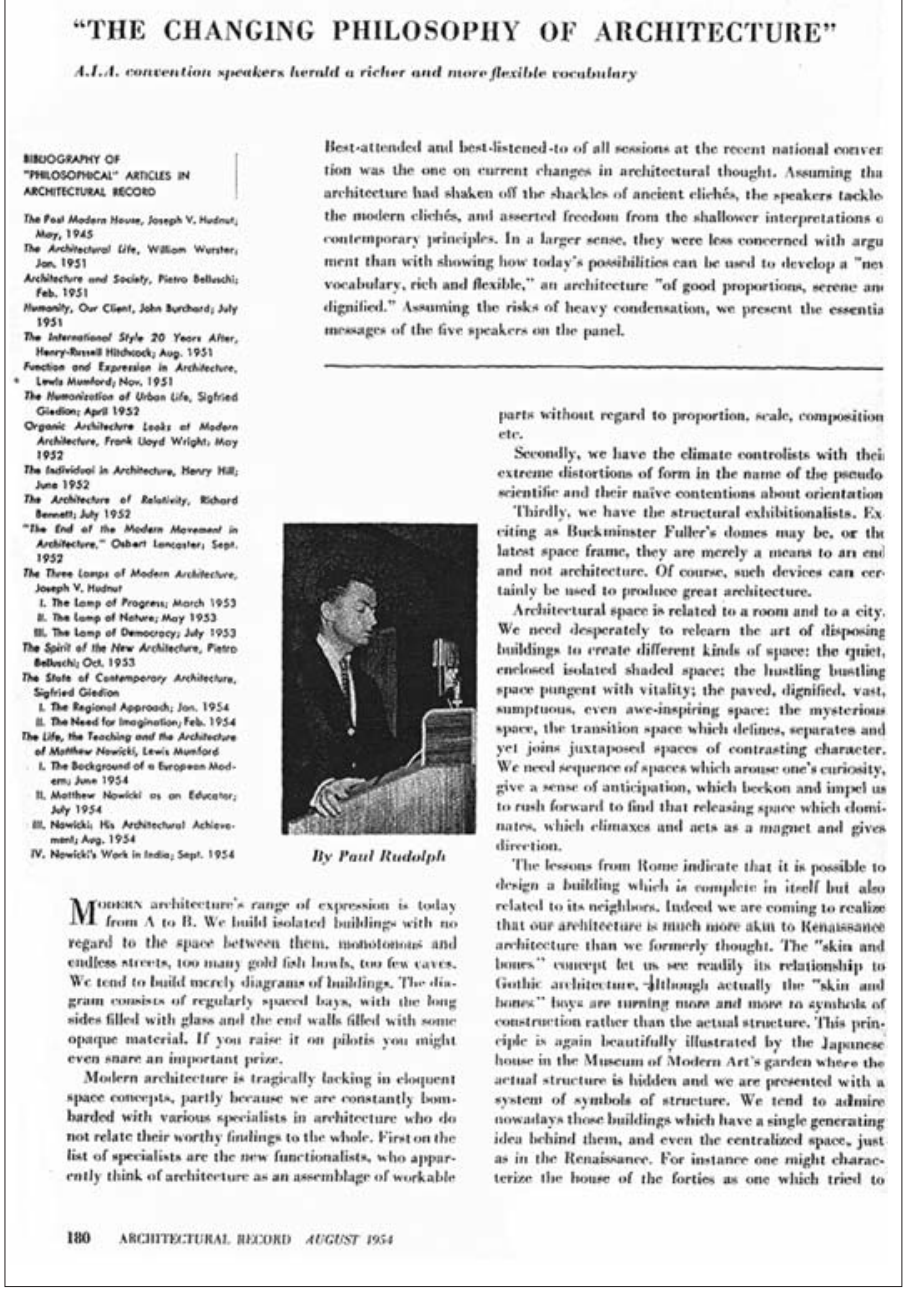

Figura 26. Cabecera del articulo "The Changing Philosophy of Architecture". En la foto Paul Rudolph durante su intervención. Rudolph et al. 1954: 80. del Estilo Internacional prestando atención a dicha "aproximación regionalista", un camino entendido por el profesor bohemio-suizo -al igual que Belluschi- como una hibridación entre las distintas opciones culturales (no sólo locales o nacionales): sugería el acercamiento entre las posiciones de la civilización occidental y, sobre todo, las del lejano oriente (asiático). Fundamentalmente, se refería a que las actitudes materialistas y racionalistas de muchas arquitecturas de Occidente habían resultado ser estériles para la vida humana, al tiempo que en estos mismos países cobraba cada vez más atención y curiosidad todo lo relativo a lo espiritual de Oriente. A diferencia de Saarinen, Giedion creyó ver en estas aproximaciones locales un camino prometedor para la arquitectura moderna de mediados de la década de 1950.

\section{The Changing Philosophy of Architec- ture (1954)}

Seis meses después de que Sigfried Giedion publicase su artículo incitando a los arquitectos a fusionar los aspectos más vanguardistas de la arquitectura moderna con sus herencias locales -o las tendencias regionalistas-, se celebraba la $85^{\mathrm{a}}$ Convención Anual del A.I.A., los días 1519 de junio de 1954, esta vez al otro lado del país: la ciudad elegida era Boston, feudo tanto de Harvard como del M.I.T. (entre otros centros universitarios) que eran sedes de difusión y desarrollo de los principios de la arquitectura moderna importada de Europa. Fruto de aquella conferencia se publicaron tres artículos en tres revistas diferentes (Architectural Forum, The Journal of the American Institute of Architects $y$ Architectural Record) con un mismo título en común: "The Changing Philosophy of Architecture" ("La filosofía cambiante de la arquitectura") (Rudolph 1954a; Rudolph 1954b; y Rudolph et al. 1954). Dicho título tenía su origen en la ponencia que Paul Rudolph había presentado en la convención del A.I.A. ese verano. Mientras que los dos primeros eran, básicamente, la transcripción escrita de dicha ponencia, el tercero en cambio recogía también parte de las conferencias de los otros participantes del simposio (José Luís Sert, Eero Saarinen, William W. Wurster y Ralph T. Walker) (figura 26).

Además, y esto era algo novedoso en este tipo de revistas profesionales, en el margen izquierdo de la primera página del artículo se presentaba una bibliografia completa de todos los artículos "teóricos" aparecidos en la propia Architectural Record entre 1945 y 1954, con los que se argumentaba dicho cambio en la filosofia de la arquitectura. Citados en el mismo orden en el que aparecían:

-“The Post Modern House", por Joseph Hudnut (mayo de 1945).

-"The Architectural Life", por William Wurster (enero de 1951).

-"Architecture and Society", por Pietro Belluschi (febrero de 1951).

-"Humanity, Our Client", por John E. Burchard (julio de 1951).

-"The International Style 20 Years After", por Henry-Russell Hitchcock (agosto de 1951).

-"Function and Expression in Architecture", por Lewis Mumford (noviembre de 1951).

-"The Humanization of Urban Life", por Sigfried Giedion (abril de 1952).

-"Organic Architecture Looks at Modern Architecture”, por Frank Lloyd Wright (mayo de 1952).

- "The Individual in Architecture", por Henry Hill (junio de 1952).

-"The Architecture of Relativity", por Richard Bennet (julio de 1952). 
-"The End of Modern Movement in Architecture", por Osbert Lancaster (septiembre de 1952).

-"The Three Lamps of Modern Architecture", por Joseph Hudnut (marzo, mayo y julio de 1953).

-"The Spirit of the New Architecture", por Pietro Belluschi (octubre de 1953).

-"The State of Contemporary Architecture", por Sigfried Giedion (enero y febrero de 1954).

-"The Life, the Teaching and the Architecture of Matthew Nowicki", por Lewis Mumford (junio, julio, agosto y septiembre de 1954)

Por otra parte, el subtítulo del artículo no dejaba lugar a dudas: "Los ponentes de la convención del A.I.A. proclaman un vocabulario más rico y flexible". En consecuencia, el texto se centraba en poner de relieve la tarea a la que debía enfrentarse la arquitectura moderna (norteamericana) de mediados de los cincuenta: asumiendo que esta arquitectura "ya se había quitado de encima los viejos clichés, los conferenciantes abordaron [la búsqueda y/o elección de] los nuevos", reivindicando la libertad a la hora de manejar "interpretaciones más ligeras de los principios contemporáneos". En general, los participantes de la convención reclamaban una arquitectura "menos preocupada con las argumentaciones teóricas, y que, en cambio, mostrase cómo las posibilidades actuales pueden ser utilizadas para desarrollar un 'nuevo vocabulario, rico y flexible', una arquitectura 'bien proporcionada, serena y digna" (Rudolph et al. 1954: 180).

Paul Rudolph incidia fundamentalmente en este aspecto. Señalaba que el margen de expresión de la arquitectura moderna en aquellos momentos iba "de la A a la B", es decir, estaba muy limitado a unos pocos "estilemas". Además, se quejaba de que los arquitectos construian "edificios aislados sin prestar atención al espacio que queda entre ellos, generando calles monótonas e interminables, con demasiadas peceras y muy pocas cuevas. Tendemos a construir meros diagramas de edificios. [...] Si además usted lo levanta sobre pilotis, incluso puede que cace algún premio importante" (Rudolph et al. 1954: 180). Creía que la arquitectura moderna carecía trágicamente de conceptos espaciales elocuentes, en parte porque los arquitectos habian sido constantemente bombardeados por varios especialistas en la materia que no habian sabido relacionar sus descubrimientos con el conjunto restante. De este modo, clasificaba a estos pseudo-expertos en: (1) los "nuevos funcionalistas", aquellos que entendian la arquitectura como el ensamblaje de una serie de piezas con usos, sin importarles la proporción, la escala, la composición...; (2) los "controladores del clima", capaces de distorsionar la forma arquitectónica en nombre de sus disputas pseudo-cientificas; y (3) los "exhibicionistas de la estructura", cuyo fin era otro distinto al de la arquitectura. Rudolph estaba convencido de que el espacio arquitectónico debía relacionar la "habitación" ("room" sic.) con la ciudad. Y en este sentido, incluso echaba mano de las lecciones de Roma para indicar que era posible diseñar un edificio en sí mismo que también tuviese en consideración a sus vecinos:

"Estamos empezando a darnos cuenta de que nuestra arquitectura se parece cada vez más a la del Renacimiento, mucho más de lo que pensábamos. El concepto de 'piel y huesos' nos permite ver inmediatamente sus relaciones con la arquitectura gótica, aunque hoy los chicos [que trabajan según el principio] de 'piel y huesos' están produciendo más bien simbolos de la construcción en vez de estructuras reales [...] quedando éstas escondidas y presentando un sistema de símbolos de estructuras". (Rudolph et al. 1954: 180)

A fin de cuentas, ¿qué pretendía decir Rudolph? Por un lado, parece que los partidarios del concepto de "piel y huesos" bien podrian asimilarse a los arquitectos americanos de raíz miesiana. En el supuesto de que se diese por buena esta hipótesis, ¿insinuaba Rudolph que entonces dichos autores estaban utilizando ciertos subterfugios o excusas -no necesariamente arquitectónicas- a modo de coartadas para justificar decisiones arquitectónicas y formales? (figura 27).

La ponencia de José Luís Sert continuaba por caminos similares a los de Rudolph. Identificaba una serie de cambios en los factores espirituales, sociales, económicos

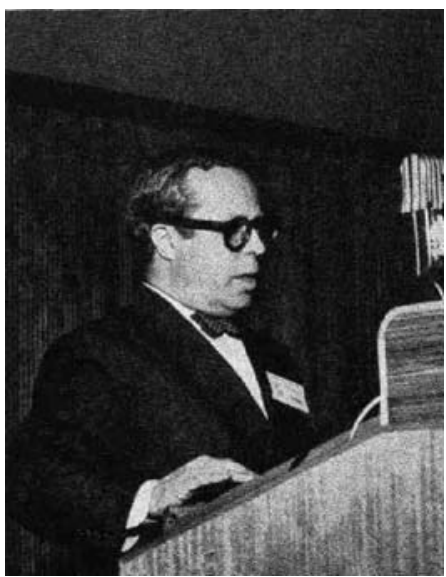


y técnicos que eran los que configuraban la arquitectura, en los que Sert creía encontrar una gran ayuda a la hora de desarrollar un estilo contemporáneo más rico en formas y con un vocabulario arquitectónico más completo:

"El nuevo y emocionante trabajo experimental [arquitectónico] frecuentemente se inclina a considerar uno o dos de esos factores, y a olvidar el resto -lo técnico y lo económico suelen sobrevalorarse, y lo espiritual suele olvidarse-. Estos factores nuevos y cambiantes también hacen que pasemos por alto los que son permanentes, aquellos sujetos al hombre y al clima. En consecuencia, perdemos la unidad y la armonía”. (Rudolph et al. 1954: 181)

Al igual que Rudolph, Sert volvía a insistir en el hecho de que los arquitectos de entonces ya se habían vuelto mucho más conscientes de que los edificios son parte de las ciudades, y que están necesariamente relacionados con su entorno. "El equilibrio [entre ambos] debe ser nuestra preocupación; necesitamos que así sea en estos días tan complicados" (Rudolph et al. 1954: 181). Terminaba su turno resumiendo:

"El funcionalismo ha sido ampliamente aceptado como el principio que ha guiado todo nuestro trabajo en arquitectura, pero ha producido unos clichés de una pobreza desastrosa. Estos clichés han sustituido a los antiguos vocabularios académicos. Hoy necesitamos un nuevo vocabulario, rico y flexible. El funcionalismo a secas no satisface nuestras necesidades. [...] Ahora debiéramos tener algo más que mera practicidad, algo que sin entrar en conflicto con lo funcional, le añada otros elementos". (Rudolph et al. 1954: 181) (figura 28)

Figura 28. Eero Saarinen durante su intervención. Rudolph et al. 1954: 82
"Zeitgeist" (el espíritu de su tiempo); (2) la integridad funcional: el funcionalismo no habia sido todo -ni podría serlo-; es decir, la función o practicidad de la arquitectura no debía ser un fin en sí mismo, sino un requerimiento más del conjunto de los elementos que configurasen un edificio; (3) el principio estructural: para Saarinen, desde el mismo comienzo de la arquitectura moderna, la integridad estructural y la claridad estructural eran dos de sus principios básicos; y (4) el reconocimiento de la importancia del espacio como un principio arquitectónico primario (por encima del de la masa). Todos estos principios no eran arquitectura en sí mismos, pero formaban una base a partir de la cual poder agregar tantos factores como se estimase oportuno con el fin de evolucionar hacia un vocabulario rico y representativo, que era lo que en el fondo parece que más le preocupaba. En este sentido, se hacía cada vez más necesaria una reevaluación continua de todas estas nociones y prácticas, hasta el punto de que el propio Saarinen, después de remarcar la importancia que entonces volvía a tener la arquitectura del Renacimiento (fundamentalmente por sus estudios acerca de las proporciones), se preguntaba: “ ¿No habremos exagerado con las ventanas tan grandes, creando tantos problemas térmicos? ¿Es la cubierta plana la respuesta a todos esos problemas?" (Rudolph et al. 1954: 182). Si bien dejaba la pregunta abierta y no ofrecía respuesta alguna, en el propio interrogante iba implícita su posición (figura 29).

Las conclusiones de William W. Wurster, similares a las de Rudolph y Saarinen, tan sólo se distinguian por añadir dos matices que, aun expresados quizás muy prematuramente, acabarian por cobrar una gran trascendencia unos diez o doce años más

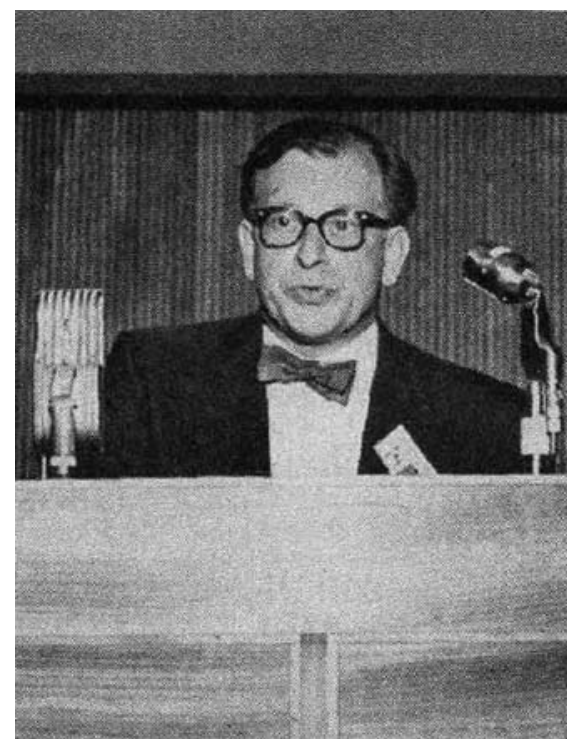

Por su parte, Eero Saarinen entendía que los factores o principios integradores de la arquitectura se habian mantenido constantes a lo largo del tiempo, aunque aclaraba que cada época que había producido su propia arquitectura había enfatizado algunos de esos principios y rechazado otros. Por este motivo, y a partir de esta premisa, Saarinen mantenía que se podía hablar de aquella "filosofia cambiante de la arquitectura". Además, daba un paso al frente enumerando los más importantes de estos principios para la creación de la nueva arquitectura moderna, que según su punto de vista eran: (1) asimilar que cada época debe crear su propia arquitectura al margen de sus avances tecnológicos, siendo expresiva de su propio 
Figura 29. William Wilson Wurster durante su intervención. (Rudolph et al. 1954: 183.)

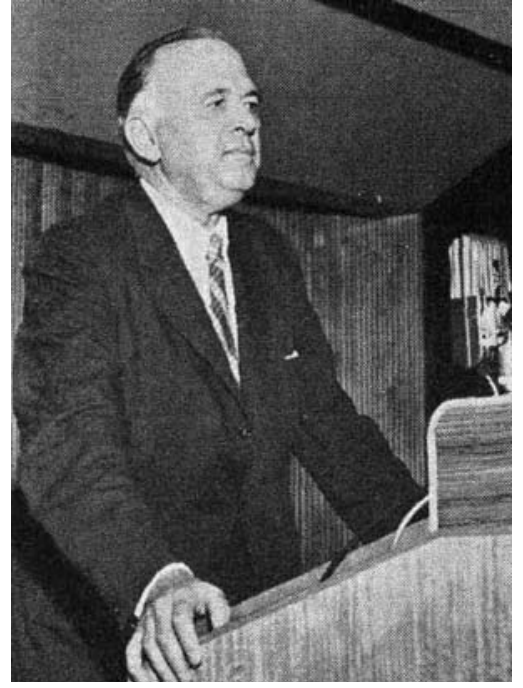

tarde: por un lado, (1) el reconocimiento de que gran parte de los cambios experimentados en la arquitectura (e incluso en las escuelas de arquitectura) tenían que ver con el compromiso establecido con el entorno -en su totalidad: físico, cultural, social...-; en comparación con el excesivo cuidado que anteriormente se había dedicado en exclusiva al edificio en cuestión, sin prestar atención al resto de elementos circundantes (arquitectónicos o no); y, tal vez como consecuencia de ello (y de un viaje que habia realizado por China y Hong Kong tan sólo unas semanas antes de la convención), (2) Wurster creía que otra de las razones por las que se estaban dando tales cambios en la filosofia de la arquitectura era la importancia, cada vez mayor, que para ésta estaban adquiriendo las vicisitudes de la vida cotidiana, de la gente común y no sólo de ciertas élites (Rudolph et al. 1954: 183). Esta misma idea llevada al campo del arte propiciaría el desarrollo de, por ejemplo, el Pop Art no mucho tiempo después.

Finalmente, la participación de Ralph T. Walker no aportaba mucho más a lo ya recogido aquí, si bien parece importante reseñar el matiz "social" (no se dirá -aún"popular") con el que caracterizaba gran parte de sus afirmaciones:

"Al tiempo que damos por hecho que la arquitectura es, sobre todo en estos momentos, una búsqueda de nuevas formas, aún persiste la duda de saber si las que tenemos ahora son lo suficientemente representativas de nuestro tiempo: quizás sean demasiado puras y geométricas, y no lo suficientemente idealistas en un sentido social más amplio". (Rudolph et al. 1954: 183)

Todas estas cuestiones, esbozadas de una $\mathrm{u}$ otra manera, siguieron muy presentes en la prensa arquitectónica estadounidense durante la década de los años cincuenta. Tanto fue así que la mayoría de las revistas de difusión de obras construidas, materiales y productos para la construcción, o de decoración (varias de ellas ya mencionadas aquí, como Architectural Record, Architectural Forum, Progressive Architecture, House Beautiful...), empezaron a incorporar algún que otro artículo de teoría o crítica en casi todos sus volúmenes, con independencia del público o lector medio de dicha publicación. En algunas ocasiones, estos sólo se hicieron eco de muchas de estas cuestiones, si bien es cierto que en otras, además, trataron de ofrecer desarrollos más profundos.

Quizás así se pueda entender mejor cómo, una década después, gran parte de aquellos debates seguian vigentes todavía. Más aún, muchos de estos conceptos (riqueza ["richness"], expresión, vocabulario flexible, símbolos arquitectónicos, historia/pasado, tradiciones, gusto popular...) serian nociones clave en el pensamiento arquitectónico de esta época, presentes de una manera global en textos capitales como Complejidad y contradicción en la arquitectura (1966) de Robert Venturi (Venturi 1966), uno de los primeros textos escritos a comienzos de los años sesenta (1962) verdaderamente teórico y crítico de la arquitectura moderna, a la vez que tremendamente propositivo y aclaratorio. En este sentido, ¿podría incluso entenderse aquel libro -y su contexto- como una consecuencia lógica del período anterior a su publicación? En otras palabras, y sin perder de vista la propia evolución de la arquitectura moderna, ¿no sería posible -acaso- entender el manifiesto venturiano como el final o colofón de una etapa, más que el principio novedoso de una nueva?

\section{Notas}

1. Para la historia de las Levittown y sus reacciones contemporáneas, véase: Gans 1982.

2. Lewis Mumford utilizó estos términos durante el simposio del MoMA de 1948.

3. Es importante recordar que la exposición viajó de manera itinerante por casi todos los rincones de los Estados Unidos de América. Véase: Riley, Terence. 1992. The International Style: Exhibition 15 and The Museum of Modern Art. Nueva York. Rizzoli.

4. Particularmente, véase: Giedion 1954b. También: Isaacs 1991.

5. Esta cuestión ha sido desarrollada ampliamente en: Pokinski, Deborah Frances. The Development of the Modern American Style. 1984. Ann Arbor (Michigan). The University of Michigan Research Press.

6. Quizás por ello, en el número siguiente de la revista, Joseph Barry publicó un artículo titulado "Reportaje sobre la batalla americana entre las casas modernas buenas y malas", poniendo de relieve la controversia entre Edith 
Farnsworth y Mies van der Rohe sobre la recién terminada casa de la doctora en Plano (Illinois), "colocada tranquilamente sobre el campo como si fuese una pecera o, mejor, como un acuario vacío sobre un soporte de acero". Para Barry era "un buen ejemplo de aquella arquitectura moderna 'mala' a la que nos oponemos". Véase: Barry 1953: 173.

7. En 1946 se fundaba la Office of Foreign Building Operations (FBO). Se trataba de una agencia del Departamento de Estado encargada de la construcción, gestión y mantenimiento de los edificios y bienes inmuebles de los Estados Unidos en el extranjero.

8. De manera paralela y secundaria, también se confeccionó un programa similar al de las embajadas pero con la construcción de varios hoteles de la cadena Hilton, fundamentalmente en las localizaciones de Atenas, El Cairo y Estambul.

9. Sobre la financiación y criterios de selección de estos arquitectos, véase: Robin, Ron. 1992. Enclaves of America. Nueva York. Princeton University Press. Y: Loeffler, Jane. 1998. The Architecture of the Diplomacy. 1998. Nueva York. Princeton Architectural Press.

\section{Bibliografia}

Andrews, Wayne. 1947. Architecture, Ambition and Americans: A Social History of American Architecture. Nueva York. Harper and Brothers.

Architecture of the Northwest. Northwest Houses. Architectural Record. Vol. 197. Abril de 1953. Nueva York.

Bangs, Jean Murray. Enero de 1948. Bernard Ralph Maybeck, Architect Comes into His Own. Architectural Record. Vol. 103. Nueva York. Págs.73-79.

Barr, Alfred H. et al. Primavera de 1948. What is Happening to Modern Architecture?. The Bulletin of the Museum of Modern Art. Vol. 15. $\mathrm{N}^{\circ}$. 3. What is Happening to Modern Architecture?: A Symposium at the Museum of Modern Art. Nueva York. The Museum of Modern Art. Págs. 4-20.

Barry, Joseph. Mayo de 1953. Report on the American Battle between Good and Bad Modern Houses. House Beautiful. Vol. 95. N ${ }^{\circ}$ 5. Los Ángeles.

Belluschi, Pietro. Febrero de 1951. Architecture and Society. Journal of the American Institute of Architects. Vol. 15. Nueva York. Págs. 8591.

Belluschi, Pietro. Agosto de 1953. The Spirit of the New Architecture. Architectural Record. Vol. 201. Nueva York. Págs. 89-97

Belluschi, Pietro. Octubre de 1953. The Spirit of the New Architecture. Architectural Record. Nueva York. Págs. 143-149

Bush-Brown, Albert. Diciembre de 1959. The Architectural Polemic. The Journal of Aesthetic and Art Criticism. Vol. 18. No. 2. Nueva York. Págs. 143-158.

Clausen, Meredith L. 1994. Pietro Belluschi. Modern American Architect. Massachusetts. The Massachusetts Institute of Technology.

Creighton, Thomas H. Mayo de 1953. Open Letter. Progressive Architecture. Vol. 34. Pág. 234.

Fitch, James Marston. Mayo de 1950. The New American Architecture Started 70 Years Ago. House Beautiful. Vol. 92. Los Ángeles (California). Págs. 134-137.

Ford, James \& Morrow Ford, Katherine. 1940. The Modern House in America. Nueva York. Architectural Book Publishing Co.

Foucault, Michel. 1972. The Archeology of Knowledge. Nueva York. Traducción de A. M.
Sheridan Smith. Pantheon Books. (Edición original: L'archéologie du savoir. 1969. Paris. Gallimard. En castellano: La arqueologia del saber. 1983. Madrid. Siglo XXI Editores).

Gans, Herbert J. 1982. The Levittowners: Ways of Life and Politics in a New Suburban Community. Nueva York. Columbia University Press.

Giedion, Sigfried. 1941. Space, Time and Architecture. The Growth of a New Tradition. Cambridge (Massachusetts). Harvard University Press. Primera edición en castellano: Espacio, tiempo y arquitectura: el futuro de una nueva tradición. 1955. Barcelona. Hoepli. Edición definitiva: Giedion, Sigfried. Espacio, tiempo y arquitectura: origen $y$ desarrollo de una nueva tradición. Traducción y edición a cargo de Jorge Sainz. 2009. Barcelona. Reverté.

Giedion, Sigfried. Enero de 1954. The State of Architecture: The Regional Approach. Architectural Record. Vol. 115. Nueva York. Págs. 132-137.

Giedion, Sigfried. 1954. Walter Gropius: Work and Teamwork. Nueva York. Reinhold.

Goldhagen, Sarah Williams y Legault, Réjean. 2000. Anxious Modernisms: Experimentation in Postwar Architectural Culture. Cambridge, Massachusetts. MIT Press.

Gordon, Elizabeth. Abril de 1953. The Threat of the Next America. House Beautiful. Vol. 95. N 4. Los Ángeles. Págs. 126-130 y 250-251. Algunos fragmentos reproducidos en: Friendman, Alice T. 1998. Women and the Making of Architecture: A Social and Architectural History. Nuea York. Harry N. Abrams. Págs. 140-141.

Hamlin, Talbot Faulkner. Enero de 1942. The Trend of American Architecture. Harpers Magazine. Vol. 184. Nueva York y Londres. Harper \& Brothers, Publishers. Págs.164171

Hitchcock, Henry-Russell Jr. Agosto de 1951. The International Style Twenty Years After. Architectural Record. Vol. 110. N ${ }^{\circ}$ 8. Nueva York. Págs. 89-97.

Hudnut, Joseph. 1949 Post-Modern Architecture. En: Hudnut, Joseph. Architecture and the Spirit of Man. 1949. Cambridge (Massachusetts). Harvard University Press. Págs. 108-119. (También en: Mumford, Lewis editor. 1952. Roots of Contemporary Architecture. Architecture and the Spirit of Man. Nueva York. Reinhold Publishing. Págs. 306-315).

Isaacs, Reginal R. 1991. Walter Gropius: An Illustrated Biography of the Creator of the Bauhaus. Boston, Massachusetts. Bulfinch Press.

Kennedy, Robert Woods. Septiembre de 1953. After the International Style, Then What? Architectural Forum. Vol. 99. $\mathrm{N}^{\circ}$ 4. Nueva York. Págs. 130-133.

Loeffler, Jane. 1998. The Architecture of the Diplomacy. 1998. Nueva York. Princeton Architectural Press.

Mallgrave, Harry Francis. 2005. Modern Architectural Theory. A Historical Survey, 1673-1968. Cambridge University Press. Nueva York.

Mock, Elizabeth (editora). 1944. Built in the U.S.A. 1932-1944. Nueva York. The Museum of Modern Art.

Morrison, Hugh S. Mayo de 1940. After the International Style -What?. The Architectural Forum. Vol. 72. No. 4. Nueva York. Págs. 345347. Reeditado en: Canizaro, Vincent B. (edi- 
tor). 2007. Architectural Regionalism. Collected Writings on Place, Identity, Modernity, and Tradition. Nueva York. Princeton Architectural Press. Págs. 280-287.

Morrow Ford, Katherine. Marzo de 1941. Modern Is Regional. House and Garden. Págs. Vol. LXXIX. 35-79.

Mumford, Lewis. 21 de enero de 1931. Two Chicago Fairs. New Republic. Nueva York. Pág. 271.

Mumford, Lewis. 11 de octubre de 1947. The Sky Line. Status Quo. The New Yorker. Vol. XXIII. $\mathrm{N}^{\circ}$ 34. Nueva York. Págs. 104-110.

Nesbitt, Kate (editor). 1996. Theorizing a New Agenda for Architecture: an Anthology of Architectural Theory 1965-1995. Nueva York. Princeton Architectural Press.

Neutra is 'Man of the Year'. 15 de agosto de 1949. Time Magazine. Vol. LIV. N ${ }^{\circ} 7$. Nueva York.

Robin, Ron. 1992. Enclaves of America. Nueva York. Princeton University Press.

Rudolph, Paul. Julio de 1954. The Changing Philosophy of Architecture. The Architectural Forum. Vol. 101. Nueva York. Págs. 120-121.

Rudolph, Paul. Agosto de 1954. The Changing Philosophy of Architecture. The American Institute of Architects Journal. Vol. 22. Nueva York. Págs. 65-70.

Rudolph, Paul et al. Agosto de 1954. The Changing Philosophy of Architecture. Architectural Record. No. 213. Vol. 116. Nueva York. Págs. 180-183.

Saarinen, Eero. Julio de 1953.Six Broad Currents of Modern Architecture. Architectural Forum. Vol. 99. $\mathrm{N}^{\circ}$ 2. Págs. 111-115.

Scully, Vincent J. Jr. 1961. Modern Architecture: The Architecture of Democracy. Nueva York. Georges Braziller.

Scully, Vincent J. Jr. Marzo de 1965. Doldrums in the Suburbs. Journal of the Society of the Architectural Historians. Vol. 24. Págs. 36-47. (Publicado también en: Perspecta. Vol. 9/10. Septiembre/octubre de 1965. New Haven (Connecticut). The Yale University School of Architecture. Págs. 281-290).

Venturi, Robert. 1966. Complexity and Contradiction in Architecture. New York. The Museum of Modern Art. (Venturi, Robert. Complejidad y contradicción en la arquitectura. 1972. Barcelona. Editorial Gustavo Gili. Colección Arquitectura y Critica).

Walker, Ralph T. Febrero de 1951. The Education Necessary to the Professional Practice of Architecture I. Journal of the American Institute of Architects. Vol. 15. $\mathrm{N}^{\circ}$ 2. Nueva York. Págs. 71-76.

Walker, Ralph T. Marzo de 1951. The Education Necessary to the Professional Practice of Architecture II. Journal of the American Institute of Architects. Vol. 15. $\mathrm{N}^{\circ}$ 3. Nueva York. Págs.119-125.

Wright, Gwendolyn. 2008. Modern Architectures in History. Londres. Graham Foundation / Reaktion Books Limited

Zevi, Bruno. 1945. Verso un'architettura organica. Turin. Einaudi. No se ha publicado ninguna otra edición y el libro fue traducidio sólo al inglés como: Towards an Organic Architecture. 1950. Londres. Faber \& Faber.

Fecha de entrega del artículo: 14/04/ 15

Fecha de aceptación:

$12 / 06 / 15$ 